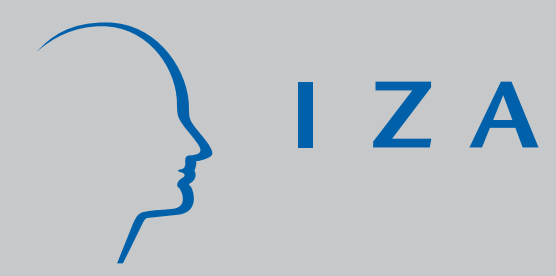

IZA DP No. 8485

Are Parental Welfare Work Requirements Good for Disadvantaged Children?

Evidence from Age-of-Youngest-Child Exemptions

Chris M. Herbst

September 2014

Forschungsinstitut

zur Zukunft der Arbeit

Institute for the Study

of Labor 


\title{
Are Parental Welfare Work Requirements Good for Disadvantaged Children? Evidence from Age-of-Youngest-Child Exemptions
}

\author{
Chris M. Herbst \\ Arizona State University \\ and IZA \\ Discussion Paper No. 8485 \\ September 2014 \\ IZA \\ P.O. Box 7240 \\ 53072 Bonn \\ Germany \\ Phone: +49-228-3894-0 \\ Fax: +49-228-3894-180 \\ E-mail: iza@iza.org
}

\begin{abstract}
Any opinions expressed here are those of the author(s) and not those of IZA. Research published in this series may include views on policy, but the institute itself takes no institutional policy positions. The IZA research network is committed to the IZA Guiding Principles of Research Integrity.

The Institute for the Study of Labor (IZA) in Bonn is a local and virtual international research center and a place of communication between science, politics and business. IZA is an independent nonprofit organization supported by Deutsche Post Foundation. The center is associated with the University of Bonn and offers a stimulating research environment through its international network, workshops and conferences, data service, project support, research visits and doctoral program. IZA engages in (i) original and internationally competitive research in all fields of labor economics, (ii) development of policy concepts, and (iii) dissemination of research results and concepts to the interested public.
\end{abstract}

IZA Discussion Papers often represent preliminary work and are circulated to encourage discussion. Citation of such a paper should account for its provisional character. A revised version may be available directly from the author. 


\section{ABSTRACT \\ Are Parental Welfare Work Requirements Good for Disadvantaged Children? Evidence from Age-of-Youngest-Child Exemptions}

This paper assesses the short-run impact of first-year maternal employment on low-income children's cognitive development. The identification strategy exploits an important feature of the U.S.'s welfare work requirement rules - namely, age-of-youngest-child exemptions - as a source of quasi-experimental variation in maternal employment. The 1996 welfare reform law empowered states to exempt adult recipients from the work requirements until the youngest child reaches a certain age. This led to substantial variation in the amount of time that mothers can remain home with a newborn child. I use this variation to estimate local average treatment effects of work-requirement-induced increases in maternal employment. Using a sample of infants from the Birth cohort of the Early Childhood Longitudinal Study, the OLS results show that children of working mothers score higher on a test of cognitive ability. However, the IV estimates reveal sizable negative effects of early maternal employment. An auxiliary analysis of mechanisms finds that working mothers experience an increase in depressive symptoms, and are less likely to breast-feed and read to their children. In addition, such children are exposed to non-parental child care arrangements at a younger age, and they spend more time in these settings throughout the first year of life.

JEL Classification: $\quad 138, \mathrm{~J} 2$

Keywords: early maternal employment, child development, welfare reform, work requirements

Corresponding author:

Chris M. Herbst

School of Public Affairs

Arizona State University

411 N. Central Ave., Suite 420

Phoenix, AZ 85004-0687

USA

E-mail: chris.herbst@asu.edu 


\section{Introduction}

The steady rise in women's labor market participation has been one of the most noteworthy economic and social transformations of the past several decades. Approximately 59 percent of women currently participate in the paid labor force, compared to 43 percent in 1970. In contrast, the fraction of men in the labor force slipped from 81 to 71 percent over the same period (U.S. Census Bureau, 2012). A key ingredient of the overall growth in female employment has been the increased labor force attachment of unmarried women with young children. Over the past three decades, the participation rate of never-married mothers with preschool-aged children increased from 44 to 68 percent, a level now exceeding their married counterparts (U.S. Census Bureau, 2012).

The phenomenal employment growth among single mothers raises questions about the implications of early maternal work for the short- and long-run development of low-income children. This issue took center stage in the debate over the U.S.'s 1996 welfare reform law, formally called the Personal Responsibility and Work Opportunity Reconciliation Act (PRWORA). Arguably the most contentious element of the PRWORA was the creation of work requirements with which adults must comply to be eligible for cash assistance. The rules stipulate that adults must be engaged in an acceptable work activity-commonly defined as participation in paid workforce-at least 30 hours per week. In addition, states have the option to levy a sanction equal to all or part of the welfare benefit on those who fail to comply with the work requirements.

Economic theory offers ambiguous predictions about the impact of the PRWORA's work requirements on child well-being. The most obvious mechanism for a positive effect is through an increase in family income, which can be used to purchase household technologies that enhance child health and development. In addition, some mothers may obtain or improve the family's health insurance coverage through an employer-provided plan. Attachment to the workforce can also benefit mothers' mental health and sense of personal control, which in turn may lead to increased household stability and higher-quality parenting. On the other hand, it is possible that the income available to invest in child development remains flat or even declines, given that welfare benefits are aggressively phased-out and that mothers might divert resources away from children in order to cover workrelated expenses (e.g., clothing, transportation, and child care). Furthermore, work requirements may decrease the quantity and quality of maternal time investments in children, while simultaneously increasing children's exposure to lower-quality non-maternal care. Finally, household stability could 
be negatively affected if the work mandates are not flexible enough to accommodate mothers with little work experience and skills as well as substance abuse or mental health issues.

Although the PRWORA's work requirements provide an interesting laboratory for studying the implications of early maternal work, identifying credible causal effects is challenging because of the complexity of measuring the work requirement rules. In particular, the PRWORA is a bundle of policy reforms-all of which were implemented contemporaneously-making it difficult to construct a measure of work requirements that is empirically untethered from other features of the legislation. This problem is exacerbated by the mid-1990's implementation of other labor market reforms, including expansions to the Earned Income Tax Credit and child care subsidies. Such difficulties provide one explanation for why only a small number of studies examine the developmental implications of welfare reform generally or work requirements specifically (Haider et al., 2003; Kaestner \& Lee, 2005; Washbrook et al., 2011).

In light of these challenges, it may be tempting to draw inferences about the impact of work requirements from the large literature studying the direct relationship between early maternal employment and child development. This research generally finds negative effects of maternal employment during the child's first year of life, with neutral or even positive effects when work begins during the second or third year of life (Bernal, 2008; Brooks-Gunn et al., 2002; James-Burdumy, 2005; Ruhm, 2004; Waldfogel et al., 2002). Many of these studies, however, analyze samples of economically diverse families, and therefore may not be appropriate for drawing conclusions about the population of families at-risk of receiving welfare. In addition, these studies must surmount a complex identification issue: mothers who decide to work early in a child's life are likely to be different from those who do not in ways that are difficult to fully capture. If these unobserved maternal differences are correlated with child well-being, the estimated effect of early maternal work may be spurious. To date, only a handful of studies attempt to overcome this omitted variables problem, most frequently by controlling for a rich set of observable family characteristics (e.g., Ruhm, 2004) or through a fixed effects estimator (e.g., Chase-Lansdale et al., 2003; James-Burdumy, 2005; Waldfogel et al., 2002). The use of instrumental variables is even less common (e.g., Bernal \& Keane, 2011; Morrill, 2011), largely because of difficulties finding credible instruments for maternal employment.

This paper examines the short-run impact of early maternal employment on the cognitive development of low-income children by exploiting an important feature of states' welfare work requirements. In particular, I use age-of-youngest-child exemptions (AYCEs) from the work require- 
ments as a source of plausibly exogenous variation in first-year maternal employment. The PRWORA authorized states to exempt adult welfare recipients from the work requirements until the youngest child reaches a certain age. This produced substantial variation in the amount of time that mothers can remain home with a newborn child, ranging from zero months in four states to 24 months in three states as of the early-2000s. In addition, many states provide mothers with different AYCE time allotments depending on the birth-order of the child. A comparatively generous exemption is provided after a woman's first child, while shorter exemptions are given after higher-order births. I use this within- and between-state variation to calculate the number of months remaining in mothers' work requirement exemption at various points throughout children's first year of life. This instrumental variable (IV) therefore generates the local average treatment effect (LATE) of workrequirement-induced increases in early maternal employment. Thus, the IV estimates in this paper are particularly important from a policy perspective.

I apply states' AYCE policies to infants and their mothers in the Birth Cohort of the Early Childhood Longitudinal Study (ECLS-B), a large nationally representative cohort study of children born in 2001. I rely on the 9-month survey, in which children were administered a cognitive ability test and mothers provided comprehensive information about the family. An advantage of the ECLS$\mathrm{B}$ is that it allows researchers to construct a detailed history of maternal labor supply since the focal child's birth. I use this information to examine two measures of early maternal employment: a binary indicator for any employment since childbirth and the cumulative number of months employed. In addition, the ECLS-B contains multiple high-quality measures of children's cognitive and behavioral development, and it provides restricted-use access to rich birth certificate information. This file identifies children's state of birth and birth-order, which are needed to construct the IV. The birth certificate file also contains a number of pre-treatment child and family characteristics that are used as covariates in the child production function.

The paper's main results are summarized as follows. I first show that states' AYCE time allotments are highly correlated with the employment decisions of disadvantaged mothers. Estimates from the first-stage equation indicate that reductions in mothers' AYCE allotment increase the likelihood of engaging in any work since childbirth $(\mathrm{F}=31.0)$ as well as the cumulative number of months employed $(\mathrm{F}=24.5)$. In addition, the $\mathrm{AYCE}$ instrument passes a number of falsification and exogeneity tests: it is uncorrelated with the work decisions of mothers ineligible for welfare, and it is uncorrelated with a variety of pre-treatment characteristics, including pre-birth maternal employ- 
ment. OLS estimates from the child ability production function suggest that children of working mothers score higher on the 9-month Bayley Short Form-Research Edition (BSF-R) test than their counterparts whose mothers do not work. However, the IV results imply that the OLS estimates are severely biased upward. When states' AYCE policies are used to instrument for early maternal work, I find that test scores are lower among children of working mothers. For example, each month of employment in the first year of life is estimated to reduce cognitive ability test scores by 0.08 standard deviations. A supplementary analysis of mechanisms finds that working mothers experience an increase in depressive symptoms, are less likely to breast-feed and read to their children, and experience behavioral complications with the child. In addition, such children are exposed to non-parental child care arrangements at a younger age, and they spend more time in these settings throughout the first year of life.

The remainder of the paper proceeds as follows. Section II provides background information on states' AYCE policies. Section III summarizes the relevant literature. Section IV introduces the ECLS-B survey and analysis sample, while Section V describes the identification strategy. The OLS and IV results are presented in Section VI, while Section VII explores mechanisms. Finally, Section VIII concludes.

\section{Background on Age-of-Youngest-Child Exemptions}

With the passage of the 1996 PRWORA, all states now require adult welfare recipients to participate in an acceptable work activity for at least 30 hours per week within 24 months of receiving assistance. ${ }^{1}$ States are given the authority to grant exemptions from the work requirements for a myriad of reasons. One such exemption, referred to as an age-of-youngest-child exemption (AYCE), allows mothers to remain home in order to provide care for an infant or toddler. ${ }^{2}$ Prior to the PRWORA, most states set the AYCE at 36 months, meaning that mothers could receive cash assistance without fulfilling a work requirement until the youngest child reached 36 months of age. However, the 1996 legislation stipulates that states may, but are not required to, exempt mothers with young children from participating in work-related activities. Not surprisingly, the law's flexibility had the effect of both reducing the average AYCE allotment and increasing the variation in AYCEs across states. These changes imply that over time a growing number of new mothers have been ex-

\footnotetext{
${ }^{1}$ However, states have the option of requiring immediate fulfillment of the work requirement. As of 2001 (the relevant year for the current analysis), most states exercised this option.

${ }_{2}$ An exemption from the work requirement may also be granted if the adult is ill or has a work-limiting disability, is caring for an ill or incapacitated family member, is ages 60 and over, and is in a specified month of a pregnancy.
} 
posed to states' work requirements, and that considerable cross-state variation now exists in the amount of time a mother is allowed to remain home with a newborn.

Table 1 summarizes the key features of states' AYCE provisions for 2001, the relevant year for the current analysis (Urban Institute, 2001). Whereas a 36-month AYCE was the norm prior to welfare reform, no state provided such a generous allotment five years after reform. The baseline AYCE ranges from zero months in (e.g., Arizona) to 24 months (e.g., Massachusetts). Four states provided new mothers with no AYCE, 19 states provided them with an AYCE of less than 12 months, and 28 states granted an AYCE of 12 or more months.

In addition to setting the amount of time allotted under an AYCE, states have the authority to establish the characteristics of families to which these allotments apply. As shown in Table 1, 13 states established policies in which the child's birth-order determines the AYCE. In particular, a comparatively generous allotment was provided to women having their first child, while mothers' higher-order births were given a substantially smaller allotment. The most common approach-taken in 12 of the 13 states adopting birth-order-based AYCEs-was to set the AYCE at 12 months for the first children and zero months for each subsequent child. The only state to deviate from this allotment was West Virginia, which provided a six month AYCE to all higher-order births.

Still another strategy, utilized in three states, was to provide a lifetime allotment of exempt time that can be used for multiple children. In each case, however, the state specified the maximum number of months that may be allocated to each newborn. Washington provided mothers with a lifetime AYCE of 12 months, stipulating that no more than four months could be expended on a single child. Such a policy implies that the AYCE in Washington was zero months starting with the fourth child. Oklahoma and Wyoming also provided a 12-month lifetime AYCE, but these states granted a maximum three month exemption up and including the fourth child. Finally, one state-South Carolina-used characteristics like mothers' age and educational attainment to establish different AYCE allotments. Here, the baseline AYCE allotment of 12 months applied only to mothers ages 26 and older who have at least a high school degree; mothers not meeting these criteria were given zero months of exempt time. ${ }^{3}$

\footnotetext{
${ }^{3}$ Given the complexity of states' AYCE provisions, a reasonable question is whether state TANF administrators are aware of the rules, understand them, and enforce them. For his own paper on AYCEs, Pingle (2003) contacted TANF administrators in 16 states to inquire about these issues. According to Pingle, state officials indicated that awareness and enforcement of AYCEs are widespread. In addition, the administrators themselves knew immediately the length of the current AYCE, and explained that it is easily applied by caseworkers and other staff to exempt mothers from the work requirements.
} 
The structure of states' AYCEs-a specified period during which mothers are able to remain home with a newborn while receiving cash assistance-naturally lends itself to comparisons with various parental leave schemes (Hill, 2012). For example, the U.S.'s Family and Medical Leave Act (FMLA) provides 12 weeks of parental leave to individuals who worked at least 1,250 hours in the previous year. Although both policies increase the amount of maternal care in the first few months of a child's life, there are several important differences. The FMLA affords three months of unpaid leave, whereas AYCEs offer a form of paid time-off that, in most states, lasts much longer than three months. ${ }^{4}$ Therefore, the FMLA is predicted to reduce family income during the leave period, while AYCEs effectively replace wage with non-wage income, although the average replacement rate is likely far below 100 percent. ${ }^{5}$ In addition, whereas the FMLA provides job-protected leave, no such guarantee exists in states' AYCEs. Indeed, the structure of AYCEs creates an incentive for women to leave a job and apply for welfare around the time of childbirth. Such mothers must subsequently engage in a job search at or near the end of the exempt time in order to maintain eligibility for cash assistance. The lack of job protection could therefore decrease maternal time with children and disrupt family routines toward the end of the exempt period.

\section{Existing Literature}

Multiple streams of research are relevant to the current study. First, there is an extensive literature studying the direct relationship between early maternal employment and child well-being. This work generally finds that full-time maternal employment in the first few years of a child's life leads to small, negative effects on early and later cognitive and behavioral development (Bernal, 2008; Brooks-Gunn et al., 2002; James-Burdumy, 2005; Ruhm, 2004; 2008; Waldfogel et al., 2002), increases in a number of adverse health outcomes (Morrill, 2011), and increases in obesity rates (Anderson et al., 2003). Much of this work analyzes samples of economically diverse children, who are less relevant to the current study's focus on the disadvantaged. An exception is a paper by Bernal and Keane (2011), who focus on children of single mothers. Their identification strategy exploits a large number of welfare reform variables, including work requirements, as instruments for maternal work

\footnotetext{
${ }^{4}$ It should be noted that, as of 2001, 14 states and the District of Columbia had more generous leave laws than the FMLA (Washbrook et al., 2011). The increased generosity was achieved by a combination of stipulating longer leave periods, allowing for paid leave, and relaxing the hours-of-work requirement. In addition, paid leave of significantly longer periods exists in many industrialized countries. Canada, for example, increased its leave period in 2000 from 25 to 50 weeks, and replaces 55 percent of earnings. Norway first introduced paid parental leave totaling 18 weeks in 1977, which was gradually raised to 35 weeks by 1992. The replacement rate in Norway is 100 percent up to a high earnings threshold.

${ }^{5}$ Indeed, U.S. welfare benefit levels tend to be quite low, and there is considerable variation across the states. In 2001 , the maximum monthly welfare benefit for a three-person family ranged from $\$ 164$ in Alabama to $\$ 923$ in Alaska. On an annualized basis, the Alabama welfare grant amounts to 14 percent of the 2001 federal poverty threshold (\$14,269 for a family with one adult and two children), while the Alaska grant amounts to 78 percent of the threshold.
} 
and child care use. The authors' IV estimates continue to show that less time in maternal care lowers scores on cognitive ability tests.

Also relevant, given its parallels to AYCEs, is the growing literature on parental leave systems. In the U.S. context, Rossin (2011) studies the impact of the federal FMLA on birth and infant health outcomes. Introduction of unpaid leave produced small increases in birth weight as well as decreases in premature births and infant mortality rates. In addition, Washbrook et al. (2011) study the developmental effects of state-based expansions to the FMLA. They find that exposure to more generous parental leave has little effect on children's cognitive and behavioral outcomes during the preschool year. Baker and Milligan's (2008; 2010; 2011) work on Canada's parental leave expansion shows increases in breast feeding, no effects on cognitive or behavioral development at age three, and negative effects on cognitive development at ages four and five. Other recent studies evaluating historical expansions to the Danish (Rasmussen, 2010), German (Dustman \& Schonberg, 2012), and Norwegian (Dahl et al., 2013) parental leave regimes generally find neutral effects on longer-run education and labor market outcomes.

Particularly relevant is the large observational literature examining states' welfare waivers and the federal PRWORA. ${ }^{6}$ However, few studies focus explicitly on work requirements, including AYCEs, or on child outcomes. ${ }^{7}$ An early study by Paxson and Waldfogel (2003) uses state-level data to examine the prevalence of child abuse and foster care placements. A key finding is that enactment of an immediate work requirement is associated with increases in the number of children in foster care. Another early paper, by Haider et al. (2003), considers the relationship between three features of states' work requirements-the presence of any work requirement, the number of work hours required, and the presence of a full-family benefit sanction-on rates of breast-feeding among new mothers. The authors find that moderate to strict work requirements are associated with sizeable reductions in breast-feeding. A more recent paper by Kaestner and Lee (2005) is one of the few to examine direct measures of child well-being, although it does not consider work requirements per se.

\footnotetext{
${ }^{6}$ In addition, there are several experimental evaluations of small scale, pre-PRWORA programs that featured a parental work requirement as a policy treatment. However, these studies are limited by their reliance on parental reports of children's school performance, as opposed to developmental metrics drawn from standardized tests or administrative data. In addition, most studies implemented random assignment when children were at least 36 months-old, and measured outcomes when they reached primary or secondary school. Therefore, the random assignment literature provides little guidance on the implications of first-year maternal employment for the short- to medium-run development. In any case, Grogger and Karoly's (2005) review of this work finds no systematic evidence that child outcomes were influenced by parents' exposure to work requirements.

${ }^{7}$ Indeed, most welfare reform studies focus on outcomes related to maternal and family well-being. Nevertheless, the work on material well-being and consumption (e.g., Meyer \& Sullivan, 2004; Kaushal et al., 2007) seems relevant, as does the work on mothers' health and health-related behaviors (e.g., Kaestner \& Kaushal, 2003; Kaestner \& Tarlov, 2006), illicit drug use (Corman et al., 2010), mental health (Rote \& Quadagno, 2011), and subjective well-being (e.g., Herbst, 2012a; 2013; Ifcher, 2011).
} 
Using National Natality Files from 1992 to 2000, their findings indicate that welfare reform led to small declines in first trimester prenatal care and increases in the incidence of low birth weight.

To my knowledge, two published papers examine the impact of AYCEs, only one of which considers direct measures of child well-being. Hill (2011) uses the June Current Population Survey between 1998 and 2008 to examine the relationship between states' AYCEs and the employment of new mothers. The author finds that mothers exposed to long exemption periods, defined as AYCEs of 12 or more months, are substantially less likely to work full-time than those not exposed to an exemption. The second paper, by Washbrook et al. (2011), also using the ECLS-B, similarly finds that mothers residing in states with longer AYCEs are less likely to work in the first year after childbirth. However, despite delaying mothers' entry into the labor market, the authors find that AYCEs are not related to intermediate determinants of child well-being (e.g., breast-feeding, maternal depression, and parenting skills), nor do they influence direct measures of cognitive and behavioral development at the start of preschool.

Both studies discussed above code states' AYCE policies through one or more dummy variables indicating the length of the baseline exemption in a given state-year cell. Specifically, Hill (2011) creates three indicators to denote families residing in states with an AYCE of zero months, three to nine months, or 12 months or more. Washbrook et al. (2011) create a single indicator to denote exposure to an AYCE of 12 months or more. Although both papers interact these variables with an indicator for marital status, the identifying variation is largely driven by the cross-state and temporal variation in the length of the baseline AYCE. This paper extends these coding schemes by first exploiting the large cross-state variation in the baseline AYCE. It then takes advantage of the differential policy treatment depending on the child's birth order. Recall that many states provide a comparatively long AYCE for mothers' first child and a significantly shorter one for each subsequent child. It also exploits states' rules on lifetime AYCE allotments, which are used to exempt mothers until the maximum number of months is reached. Finally, the paper uses information on the focal child's age-at-assessment to distinguish between mothers with varying AYCE allotments simply because they were interviewed at different times. Together, these sources of variation produce an individual-level measure of mothers' remaining AYCE allotment at a given point in time.

\section{Data}

The primary dataset for this research is the Birth cohort of the Early Childhood Longitudinal Study (ECLS-B). The ECLS-B is a nationally representative sample of approximately 11,000 children born 
in 2001. The survey was designed to track children's early home and educational experiences by conducting detailed parent and child care provider interviews and initiating a battery of child assessments at various points between birth and kindergarten entry. The first wave of data collection occurred when focal children were 9-months-old (2001-2002), with follow-up surveys implemented at 24-months (2003), during the preschool year (2005-2006), and after kindergarten entry (2006-2007).

The analysis sample is comprised of children from the 9-month wave of data collection. In particular, a home visit was initiated on or near the focal child's 9-month birthday to administer cognitive and psychomotor assessments and to conduct a 60 -minute parent interview. ${ }^{8}$ To craft the analysis sample, I exclude children whose mother is younger than 18 years old (216 observations) as well as those with missing information on maternal employment status (38), marital status at childbirth (73), educational attainment at childbirth (154), and the number of previous live births (24). I also drop children with missing information on the 9-month cognitive assessment (484). Mothers younger than 18 are omitted in light of states' minor parent provisions, stipulating that minors must reside in the home of a parent or guardian and remain enrolled in school in order to receive welfare benefits. Thus, such individuals are not likely to be influenced by states' work requirements. Also omitted are mothers enrolled in classes at a school, university, or college $(1,083)$. Many states do not count participation in post-secondary education as an acceptable work activity, making it unlikely that such mothers would be influenced by work requirements. ${ }^{9}$ After applying these restrictions, the result is an analysis sample of 8,558 children. ${ }^{10}$

To fix attention on the group of children whose mothers are potentially eligible to receive welfare, and thus likely to be influenced by states' work requirements, I split the sample according to mothers' educational attainment and marital status. In particular, I define the group of potentially eligible mothers as those with less than a college degree or those who are unmarried. Such definitions are fairly standard in the U.S. welfare reform literature (e.g., Herbst, 2013a; Bitler et al., 2005; Fang \& Keane, 2004; Grogger, 2003; Meyer \& Rosenbaum, 2001; Schoeni \& Blank, 2000). For the purposes of conducting sensitivity and falsification tests, I define the group of mothers ineligible to receive

\footnotetext{
${ }^{8}$ The parent survey collected detailed information on the demographic characteristics of the focal child and family, the labor market and program participation characteristics of the mother, family well-being and routines, and child care participation. ${ }^{9}$ In robustness checks, I experiment with a number of alternative definitions of the education restriction. I first relax the restriction, and allow those enrolled in courses to remain in the sample. The OLS and IV results are similar to those reported in the paper. Using the Urban Institute's Welfare Rules Database for 2001, I then code states' work activity rules, omitting only those enrolled in classes and residing in states that do not allow post-secondary education as an acceptable activity. The results are not substantially different using this definition. Finally, I attempt to identify and omit only full-time students, defined as those who are enrolled in courses and are not working for pay. Once again, the results are similar to those reported in the paper.

${ }^{10}$ I drop a small number of additional children for very minor reasons.
} 
welfare as those with at least a college degree and those who are married. A key motivation for using educational attainment and marital status to stratify the sample is that the welfare reform literature is unsettled as to the most appropriate characteristics for identifying welfare-eligible (treated) and ineligible (untreated) women. Although it is common to use both educational attainment and marital status to create the groupings (e.g., Herbst, 2013a; Hill, 2012; Bitler et al., 2005; Kaushal \& Kaestner, 2005), some studies use only education (e.g., Schoeni \& Blank, 2000), while others use only marital status (e.g., Grogger, 2003; Meyer \& Rosenbaum, 2001; Pingle, 2003). Relying on both characteristics therefore seems like the most comprehensive method for distinguishing between potentially eligible and ineligible families.

To construct these groups, one option is to use information on mothers' educational attainment and marital status as of the 9-month assessment. However, applying these characteristics after the introduction of the policy treatment (i.e., exposure to work requirements) would lead to a problem of endogenous sample selection if these characteristics are influenced by welfare reform. Such concerns seem warranted in light of evidence from Bitler et al. (2004; 2006) that welfare reform altered marriage and divorce rates as well as children's family structure. Fortunately, the ECLS-B makes available to researchers a variety of information from children's birth certificate, including the biological mother's educational attainment and marital status. ${ }^{11}$ Information collected at childbirth alleviates concerns over endogenous sample selection because the maternal characteristics are measured simultaneously with the initiation of the AYCE allotment. Of the 8,558 children in the sample, 6,207 are included in the welfare-eligible subsample, and 2,351 are included in the non-eligible subsample. $^{12}$

The primary outcome is a measure of children's early cognitive ability from the Bayley Short Form-Research Edition (BSF-R) test, administered at the 9-month assessment. This instrument was designed specifically for the ECLS-B and includes a subset of items from the full Bayley Scales of Infant Development-Second Edition (BSID-II), a widely used measure of early cognitive and motor development. Although the original BSID-II was designed to be completed in a clinical setting, the BSF-R was developed for ease of administration in a home environment. This study examines only

\footnotetext{
${ }^{11}$ Birth certificate information is made available to researchers through a restricted-use data license. The marital status variable on the birth certificate distinguishes between mothers who are married and unmarried. It does not provide information on whether the mother is never married, divorced, separated, or widowed.

${ }^{12}$ Given the definitional ambiguities associated with creating welfare-eligible and -ineligible groups, it reassuring that the TANF participation rate is substantially higher for the former group (11.5 percent) than for the latter group (0.4 percent). The TANF participation rate for mothers unmarried at birth is 20.8 percent, and that for mothers with less than a college degree at birth is 11.6 percent.
} 
the cognitive component of the BSF-R, containing 31 items during the 9-month assessment. The test measures several dimensions of early cognitive and language ability, including memory, preverbal communication, expressive and receptive vocabulary, reasoning and problem solving, and concept attainment. Item response theory (IRT) scale scores are used in the analysis.

This study examines two measures of early maternal employment. First, I test a binary indicator that equals unity if a given mother ever worked since the focal child's birth, and zero if the mother did not work since childbirth. At the 9-month assessment, mothers were asked if they worked for pay during the previous week. Among those not currently working, a follow-up question was asked whether they had done so since the focal child's birth. Children whose mothers answered affirmatively to either question were coded a value of one on this variable; all others were coded a value of zero. Approximately 58 percent of mothers in the welfare-eligible subsample were ever employed since childbirth, compared to 63 percent of mothers in the welfare-ineligible subsample. Second, I test a measure of cumulative employment, defined as the total number of months a given mother was employed as of the 9-month assessment. I construct this variable by combining information on the child's age (in months) and mothers' employment status at the 9-month assessment with a survey item asking about the (child's) age at which the mother returned to work. ${ }^{13}$ The average welfare-eligible mother worked about 4.1 months since childbirth, only slightly less than the 4.5 months worked by the typical non-eligible mother. ${ }^{14}$

Figure 1 displays the evolution in maternal employment throughout the first year of the child's life. In particular, it shows the cumulative proportion of welfare-eligible and -ineligible mothers who started working in the first 12 months after childbirth. Overall, maternal employment rates increased rapidly throughout the first six months of life, after which the transition into work begins to slow. Fully one-quarter of eligible and ineligible mothers began working within two months of childbirth, but then the employment trends begin to diverge. By the time children are six months old, 50 percent of welfare-eligible mothers had begun working, compared to 57 percent of their ineligible counterparts. A difference is still evident at 12 months, when 57 and 63 percent of mothers had started to work, respectively.

Table 2 provides summary statistics for the subsample of welfare-eligible families. Children whose mothers did any work since childbirth scored about 1.5 points higher on the BSF-R than their

\footnotetext{
${ }^{13}$ Mothers both currently employed (i.e., working as of the 9 -month assessment) and ever employed since childbirth (but not currently working) were asked about the child's age at which maternal employment began.

${ }^{14}$ The mean months of work reported in the text includes mothers who did not work. When the means are conditioned on doing any work, welfare-eligible and -ineligible mothers worked 7.1 months, on average, since childbirth.
} 
counterparts whose mothers did not work. Working mothers are less likely to be high school dropouts, have fewer children, and are less likely to receive benefits from the Women, Infants, and Children program (WIC). In addition, total annual income in households with working mothers is about 15 percent higher on average. Finally, the children of employed mothers appear to be in better baseline health: they are less likely to be classified as low birth weight and less likely to be born prematurely. These descriptive data suggest that children of working mothers are more economically advantaged than their non-working counterparts, a pattern which may explain the test score gap in favor of the former group. The relative economic advantage of working families also highlights the central concern associated with OLS estimates of early maternal employment. In particular, working mothers are likely to be positively selected in ways that are difficult to fully account for, leading to OLS estimates that are biased upward.

\section{Identification Strategy}

It is useful to begin by specifying an OLS regression model of the child's cognitive ability production function:

$$
\ln \left(A_{\text {is }}\right)=\beta_{1} W O R K_{\text {is }}+\mathbf{X}^{\prime} \eta+\mathbf{Z}^{\prime} v+\varepsilon_{\text {is }}
$$

where $i$ indexes children and $s$ indexes state of residence; $\ln (A)$, the natural logarithm of the child's BSF-R score at the 9-month assessment, is a proxy for latent cognitive ability; and WORK is either the binary indicator for any maternal employment since childbirth or the measure of cumulative employment. The $\mathbf{X}$ is a matrix of observable family and child determinants of cognitive ability, $\mathbf{Z}$ indicates a set of region of birth indicators as well as a large number of state policy, economic, demographic, and political characteristics; and $\varepsilon$ captures the unobserved determinants of child ability. Equation (1) may be estimated separately on the subsamples of ECLS-B children residing with welfare-eligible and -ineligible mothers.

For the binary measure of WORK, the coefficient of interest, $\beta_{1}$, provides an estimate of the average difference in BSF-R scores between infants whose mothers worked and did not work since childbirth. ${ }^{15}$ Given that test scores are measured on or near the child's 9-month birthday, $\beta_{1}$ should be interpreted as the short-run effect of early maternal work. The coefficient $\beta_{1}$ is identified through a cross-sectional comparison of children's BSF-R scores, a fairly common empirical strategy in the

\footnotetext{
${ }^{15}$ For the measure of cumulative employment, $\beta_{1}$ is the average change in test scores associated with a one-month increase in maternal employment.
} 
early maternal employment literature. However, even with a richly specified production functioncontaining detailed child and family controls-concerns remain that working and non-working mothers are different in ways that influence child ability. One possibility is that some mothers have skills (e.g., human capital) or personality traits (e.g., social skills or higher motivation) that are positively correlated with labor market participation and child ability. If these maternal characteristics are omitted from equation (1), estimates of $\beta_{1}$ will be biased upward. On the other hand, it is conceivable that less-skilled mothers are more likely to work because they seek to offset the social and economic disadvantages that exist in the home environment. Failure to control for these characteristics in equation (1) would impart a downward bias on $\beta_{1}$. The summary statistics in Table 1-establishing that working mothers are more advantaged-suggest that the net effect of the unobservables is to bias $\beta_{1}$ upward.

One method for dealing with this omitted variables problem is to leverage quasi-random variation in WORK through an instrumental variable (IV). This approach will produce consistent estimates of the impact of early maternal work if at least one variable is found to satisfy two conditions: (i) it is highly correlated with mothers' work decisions, and (ii) it is orthogonal to child ability except through its relationship with maternal work. In this paper, I attempt to identify the causal impact of early maternal employment by exploiting variation in states' AYCEs from the welfare work requirements. Specifically, AYCEs are expected to influence maternal employment decisions-such that smaller allotments of exempt time should increase the probability of working after childbirth-but are not expected to directly influence child ability.

To construct the instrument, which I denote as EXEMPT in the regression models, I begin by coding each state's AYCE (in months) in effect during 2001. Detailed information on the AYCEs is available through the Urban Institute's Welfare Rules Database (Urban Institute, 2001). The AYCE data are then merged to the analysis sample based on the child's state of residence at birth. For families residing in one of the 34 states providing the same AYCE allotment to mothers regardless of the number of previous births, EXEMPT is generated by subtracting the state's AYCE allotment from the child's age (in decimal months) at the 9-month assessment. For families residing in one of the 14 states that vary the AYCE allotment by the number of previous births, I identify the child's birth-order from the birth certificate file, and, in conjunction with the child's age-atassessment, I calculate the appropriate value for EXEMPT. In particular, I identify the AYCE al- 
lotment that applies to a given child based on the birth-order, and then subtract that allotment from the child's age. Finally, for families residing in the three states (Oklahoma, Washington, and Wyoming) providing a lifetime AYCE allotment, I take advantage of the rule that a mother cannot allocate more than a specified number of months to a single child. Recall that all three states provide a lifetime AYCE of 12 months, with Oklahoma and Wyoming granting a maximum of three months for each child and Washington granting a maximum of four months. I assume that mothers take the maximum allowable AYCE for each child until the lifetime limit is reached, beyond which mothers are not given an exemption for having additional children. Once the appropriate AYCE allotment is determined, EXEMPT is calculated in the same manner as above.

Given that EXEMPT is calculated in relation to the child's age, negative values indicate that a mother has time remaining in the work requirement exemption (because the AYCE allotment exceeds the child's age), while positive values indicate that a mother exhausted the exemption (because the child's age exceeds the AYCE allotment). Variation in EXEMPT is derived from three sources. The chief source of variation comes from cross-state differences in the generosity of AYCE allotments. A second source of variation comes from the birth-order of focal children. Specifically, children within a given state can be assigned different values on EXEMPT depending on the AYCE allotment that applies to their birth-order. Both components are determined at the time the child is born. Thus it is assumed that forward-looking mothers, who are provided with different stocks of exempt time, have different horizons over which to make work and welfare participation decisions. A smaller stock of exempt time should increase (decrease) the amount of time mothers spend working (receiving welfare), especially in the first year of life.

Lastly, additional within-state variation is created by virtue of the differential ages at which children were assessed (and parents answered questions about their current employment status as well post-birth employment history). Although ECLS-B administrators intended to assess children when they were nine months old, in practice administrators were unable to accomplish this. Indeed, children were assessed between the ages of six and 22 months, although the median age-atassessment is 10 months. ${ }^{16}$ This is a potentially important source of variation because children born in the same state and with the same parity will be assigned different values on EXEMPT if they happen to be assessed by ECLS-B administrators at different ages. It is also a plausibly exogenous

\footnotetext{
${ }^{16}$ Variation in age-at-assessment is evident within states as well. In California, for example, children were assessed between the ages of eight and 21 months, while those in Texas were assessed between seven and 16 months.
} 
source of variation because it is unlikely that parents selected an assessment date based on the focal child's cognitive ability. Of course, this component is not determined at the time the child is born, nor is it known by mothers at what age the child will be assessed. As a result, this source of variation is not likely to be correlated with work and welfare decisions in the period proximate to the child's birth. Age-at-assessment, however, is likely to be correlated with current decision-making because it is assumed that mothers are aware of the child's age relative the AYCE allotment (determined at birth), and they are able to estimate the remaining stock of exempt time. Together, the three sources of variation in EXEMPT-two of which are determined at childbirth and one of which is determined at the time the child is assessed-align with the measure of early maternal employment, which commingles information on mothers' work history with that on mothers' current work status.

For the sample of welfare-eligible families, the median on EXEMPT is 5.4 months $(S D=6.9)$, with a minimum of -16.8 and a maximum of 21.8 , indicating that the typical welfare-eligible mother had exhausted the AYCE allotment by over five months at the 9-month assessment. Figure 2 presents a richer picture of the variation in EXEMPT. In particular, it plots in descending order the median number of months remaining in families' AYCE allotment, aggregated to the state-level. For presentation purposes, Figure 2 is constrained to the 15 states with the largest (Texas to West Virginia) and smallest (Washington to Idaho) median AYCE allotment. It is clear that substantial variation exists in EXEMPT: at the 9-month assessment, the median family in Texas and Massachusetts had approximately 14 months remaining in its AYCE from the work requirements, while that in Maryland and Idaho had exhausted the AYCE by at least 11 months.

How much of this variation is driven by cross-state differences in AYCE policies? To investigate this, I produce separate density plots on EXEMPT for families exposed to less generous AYCEs-defined as an AYCE of four months or less-and families exposed to more generous AYCEs-defined as an AYCE of more than four months. These definitions are generated from states' baseline AYCE allotments and, if applicable, the birth-order-based allotments. As shown in Figure 3a, the entire distribution of EXEMPT for families exposed to less generous AYCEs resides to the right of the break-even point (i.e., zero months). Indeed, as of the 9-month assessment, over threequarters of such families exhausted the AYCE by five- to 10-months. On the other hand, Figure 3b shows that two-thirds of families exposed to more generous AYCEs had between one- and fivemonths remaining in their allotment. Thus, variation in EXEMPT strongly corresponds to the two key sources of (policy-induced) variation in states' AYCEs. 
To check whether the first identifying condition holds, I provide graphical and regressionbased evidence on the fist-stage relationship between EXEMPT and early maternal employment. Figures 4a and 4b display raw (unconditional) results for the binary indicator of any maternal employment and the measure of cumulative employment, respectively. Each dot represents the unadjusted mean for maternal employment within one-month bandwidths of EXEMPT. ${ }^{17}$ The solid line shows the estimated best linear fit. Recall that EXEMPT is created by subtracting the relevant AYCE allotment from the focal child's age. Therefore, increases in the variable coincide with reductions in the time remaining in the work requirement exemption. Both figures reveal a fairly strong relationship between AYCEs and early maternal employment: rates of work participation and months of work are greater among mothers faced with smaller AYCE allotments.

Table 3 formalizes the graphical evidence by presenting conditional estimates from the following first-stage equation:

$$
W O R K_{\text {is }}=\psi_{1} E X E M P T_{\text {is }}+\mathbf{X}^{\prime} \eta+\mathbf{Z}^{\prime} v+\mu_{\text {is }}
$$

where WORK is the measure of early maternal employment and EXEMPT, the IV, captures the number of months remaining in a given mother's AYCE allotment as of the 9-month assessment. All models include the full set of control variables appearing in equation (1), and the standard errors are adjusted for clustering within date of assessment cells. The variables in $\mathbf{X}$ and $\mathbf{Z}$ are listed in the notes to Table 3. Column (1) shows the estimates for the binary indicator of any work, while column (2) shows the estimates for cumulative (i.e., months of) work. The estimates in Panel A are derived from the welfare-eligible subsample, and those in Panel B provide a falsification test by showing the analogous results for the welfare-ineligible subsample.

Columns (1) and (2) provide evidence of a strong first-stage relationship between EXEMPT and WORK. In particular, increases in EXEMPT-representing reductions in the remaining AYCE allotment-are positively associated with the likelihood of engaging in any work as well as the cumulative months of work as of the 9-month assessment. A one-month reduction in the AYCE increases the likelihood of employment by 0.6 percentage points [Panel A, column (1)] and increases months of employment by 0.04 months [Panel A, column (2)]. With F-statistics of 31 and 25, respectively, EX$E M P T$ should provide sufficient statistical leverage to identify WORK in the second-stage equation. Results in Panel B provide a falsification test by estimating the first-stage equation on the subsam-

${ }^{17}$ Although the minimum and maximum values on EXEMPT are -16.8 and 21.8 , respectively, I constrain the figures to -15.0 to 15.0 , given there are very few observations that lie outside these boundaries: 47 observations are reside below -15.0 and 61 observations reside above 15.0. The formal first-stage regressions, however, take full advantage of the values on EXEMPT. 
ple of children of welfare-ineligible mothers. If EXEMPT does in fact capture mothers' exposure to AYCEs, then one would expect EXEMPT to be unrelated to the work decisions of mothers not atrisk of receiving welfare. Results in columns (1) and (2) suggest that EXEMPT passes the falsification test: the coefficients are substantially smaller in magnitude than their counterparts from the welfare-eligible subsample, and neither is statistically significant ( $\mathrm{F}=1.3$ and 1.5, respectively).

The model shown in column (3) provides an additional robustness check. The dependent variable is a binary indicator equal to unity if a given family received cash assistance at any point since the child's birth. The expectation is that reductions in the AYCE allotment should reduce the likelihood of receiving welfare in the eligible subsample, while having no effect on participation in the ineligible subsample. Both predictions are borne out. Specifically, the coefficient in Panel A, based on the welfare-eligible subsample, implies that a one-month reduction in the AYCE allotment reduces the likelihood of receiving welfare by 0.2 percentage points, a result that is statistically significant. On the other hand, the coefficient in Panel B, from the subsample of ineligible families, implies a substantially smaller and imprecisely estimated reduction in welfare receipt.

To serve as a valid instrument, EXEMPT must also fulfill the second identifying condition, in that it must be appropriately excluded from the child's cognitive ability production function. In other words, EXEMPT can only influence child well-being indirectly, through its effect on maternal employment. There are a few concerns with using AYCEs as an instrument for early maternal work. First, variation in EXEMPT is generated in part from a number of child- and family-level characteristics. Recall that EXEMPT is created not just from cross-state variation in AYCE allotments, but also from the child's birth-order and age-at-assessment. It is conceivable that both characteristics are related to mothers' work decisions and child well-being. Indeed, there is a well-documented relationship between birth-order and maternal time inputs (Lehman et al., 2012; Monfardini \& See, 2012) as well as child outcomes (Black et al., 2005). A related issue is the potential endogeneity of fertility decisions, in which unobserved maternal characteristics are related to the number and timing of births. I deal with these complications by including in $\mathbf{X}$ explicit controls for the child's age at the 9month assessment, entered in decimal months and a quadratic in months, as well as a full set of birth-order fixed effects.

In addition, the baseline model includes a number of pre-treatment maternal characteristics that may be correlated with fertility and employment preferences. In particular, I control for mothers' age (and age-squared) at birth, marital status at birth, and educational attainment at birth. I 
also account for mothers' use of tobacco products during the pregnancy, as this may proxy the quality of maternal time inputs, including difficult-to-measure human capital and personality traits as well as the child's stock of early health and ability. Dummy variables for low birth weight and premature births are also included because they are viewed as more explicit controls for early child health and development as well as the family's material resources. As an additional control for difficult-tomeasure family characteristics, I include the child's birth month in the baseline model. Indeed, Buckles and Hungerman (2010) document strong seasonal patterns in the socioeconomic characteristics of women giving birth at different times through the year. Mothers giving birth in the first quarter of the year are more likely to be teenagers, unmarried, and high school drop-outs.

The second concern is that the influence of AYCEs on maternal employment could be confounded by other forms of leave-taking, such as that induced by the FMLA. Stated another way, the IV estimate on WORK could be as much a reflection of the FMLA's impact on maternal work as it is states' AYCE policies. However, there are a few intuitive reasons why the FMLA is not empirically commingled with states' AYCE policies. Since the FMLA is a federal policy, there is by definition little cross-state variation in its characteristics. Furthermore, although a number of states implement their own (expanded) parental leave policy, only a small subset of those states alter the leave-taking period to be longer than the FMLA's three months. A related point is that the FMLA's three months of allowable leave is substantially shorter than the period granted under states' AYCEs. Recall that over half of states in 2001 provided an AYCE of at least 12 months. Finally, given the FMLA's firm size (50) and hours-of-work requirements (1,250 hours), many low-income mothers are not eligible for leave. ${ }^{18}$

Despite these policy differences, I take steps to ensure that the FMLA and related state leave policies do not confound the IV estimates on WORK. I included in the baseline model a dummy variable that equals unity for families residing in states that provide more generous parental leave provisions than the FMLA. The coding for this variable is consistent with the Washbrook et al. (2011) definition. I also experiment with a narrower version of the dummy, assigning a value of one to families in states with longer leave periods than the standard FMLA period. Doing so does not change the results. In a robustness check, I then exploit an ECLS-B survey item from the 9-month assess-

\footnotetext{
${ }^{18}$ The hypothesized lower eligibility rate among low-income mothers is borne out by data on actual leave-taking. At the 9month assessment, mothers were asked whether they had taken maternity leave. Full 61 percent of mothers in the welfareineligible subsample claimed to have taken maternity leave, whereas substantially fewer welfare-eligible mothers-41 percent-did so.
} 
ment that asks mothers whether they had taken maternity leave since the focal child's birth. Models that include a binary indicator for leave-taking yield first-stage and IV estimates similar to those reported in the baseline models.

Given that an important source of variation in EXEMPT is the cross-state differences in AYCE allotments, another concern is a type of policy endogeneity, in which AYCEs are correlated with other state-level social policy, economic, or demographic characteristics that influence child ability. Of particular concern is the potential correlation of AYCEs with other features of welfare reform. For example, political decisions regarding the generosity of AYCE allotments could be related to the stringency of benefit sanctions or time limits. In addition, it is possible that states with more favorable economic conditions provide less generous AYCE allotments. If these unobserved state characteristics are correlated with child ability, then EXEMPT would be an invalid instrument. I attempt to handle policy endogeneity by incorporating in the baseline model a set of region of birth indicators as well as 22 state-level controls. ${ }^{19}$ These variables describe several dimensions of states' social policy, economic, demographic, and political environment.

Some may argue that state fixed effects are more robust controls for policy endogeneity. In this context, however, fixed effects may not be beneficial, or even appropriate. Since variation in EXEMPT is derived in large part from cross-state differences in AYCE allotments, it is not surprising that the fixed effects explain most of its variation. Indeed, the $\mathrm{R}^{2}$ from a regression of EXEMPT on a set of state of birth fixed effects is 0.81 . Including fixed effects therefore leaves little variation in the instrument to identify WORK in the second-stage equation. ${ }^{20} \mathrm{In}$ contrast, the $\mathrm{R}^{2}$ from a regression of EXEMPT on the region of birth indicators and 22 state-level controls is 0.45 . Furthermore, although the fixed effects are highly correlated with EXEMPT, excluding them would induce bias only if they are systematically related to cross-state differences in child ability, conditional on the observable family and child controls. The state fixed effects do not appear to be strongly correlated with child cognitive ability in the ECLS-B. In a regression of the 9-month BSF-R score on the state-

\footnotetext{
${ }^{19}$ The state controls include a dummy variable for more generous parental leave provisions than the FMLA, the log of federal and state Child Care and Development Fund (CCDF) expenditures per child, the log of the maximum Earned Income Tax Credit (EITC) benefit, the maximum AFDC/TANF benefit for a three-person family, a dummy variable for states that operate a formal welfare diversion program, a dummy variable for states with a lifetime time limit on welfare receipt, a dummy variable for states with a full benefit sanction in the first instance of non-compliance with the work requirements, a dummy variable for states operating a family cap policy, the state unemployment rate, the log of weekly earnings in the service sector, state GDP per capita, the log of per capita income, the log of population density, the log of total population, percent state population of women ages 15 to 39, percent state population of women ages 40 to 64 , percent state population of whites, percent of state population under age 5, percent of state population uninsured, a dummy variable for states with a Republican governor, a dummy variable for gubernatorial election years, and the percent voting Republican in the previous Presidential election.

${ }^{20}$ In an IV regression with state fixed effects, the F-statistic on EXEMPT in the first-stage equation is essentially zero $(\mathrm{F}=0.49)$. As a result, the standard error on WORK in the second-stage is over 500 percent larger than that from an IV model that includes the region of birth indicators and 22 state-level controls.
} 
of-birth fixed effects, the state indicators explain only six percent of the variation in test scores. Furthermore, the incremental $\mathrm{R}^{2}$ associated with adding the fixed effects (to a model that includes the family and child controls) is 1.3 percent. Importantly, the fixed effects do not meaningfully outperform the region indicators and state-level controls: the incremental $\mathrm{R}^{2}$ associated with these controls is 0.8 percent.

The exogeneity of EXEMPT can be tested indirectly by examining its relation to family characteristics that should not be influenced by states' AYCEs. One way to conduct the test is by estimating reduced form relationships between EXEMPT and a set of pre- or at-birth maternal and child characteristics. The scatterplots in Figures 5a through 5h show these relationships. ${ }^{21}$ Each plot represents the residualized mean for a given characteristic in one-month bandwidths of EXEMPT. The residuals were generated from an OLS regression of each characteristic on EXEMPT controlling only for the region of birth indicators and the 22 state-level variables. The plots also contain the best linear fit line constructed from the regression, whose slope represents the coefficient on EXEMPT. It is reassuring that EXEMPT is unrelated to an array of background characteristics that may influence child well-being. Indeed, the binned means for each characteristic are essentially flat over the distribution of EXEMPT. That the child and maternal characteristics are unrelated to the instrument in a regression that controls only for the state characteristics suggests that they are sufficient for removing policy endogeneity, and that state fixed effects are not necessary to maintain the validity of EXEMPT.

Table 4 formalizes the scatterplots by estimating reduced form regressions accounting for the full set of controls. In no case is EXEMPT statistically significant. It is particularly encouraging that it is uncorrelated with pre-birth maternal employment, in light of the strong correlation between preand post-birth employment. ${ }^{22}$ In addition, the instrument is uncorrelated with difficult-to-measure maternal and child ability endowments, as captured by grandparents' educational attainment. It is also unrelated to the child's season of birth, which is influenced by a complex set of maternal preferences and human capital characteristics that may influence child development (Buckles \& Hungerman, 2010). Finally, EXEMPT is orthogonal to the child's birth weight and premature birth status, which are shown to have implications for a number of outcomes (e.g., Black et al., 2007; Case et al.,

${ }^{21}$ From Figure 5a to 5h, the characteristics are: whether the mother worked at all in the year prior to childbirth, whether the mother attended 16+ prenatal doctor's visits, whether the mother lived with the biological father until age 16 , whether the child's grandmother was a high school drop-out, whether the child's grandfather was a high school drop-out, whether the family received WIC in the previous 12 months, whether the child's gender is male, and whether the child's race is black. ${ }_{22}$ Indeed, the post-birth employment rate (i.e., any work) is 72 percent among mothers who worked in the year before the child's birth. It is 26 percent among mothers who did not work in the year prior to childbirth. 
2004). Together, these results provide evidence in favor of the validity of EXEMPT as an identifying instrument.

\section{Estimation Results \\ Baseline OLS and IV Estimates}

Table 5 presents the main OLS and IV estimates of the impact of early maternal employment (WORK) on children's BSF-R scores $[\ln (A)]$. Columns (1) and (2) provide the OLS results for the binary indicator of any work and the measure of cumulative work, respectively. Column (3) displays the reduced form results, in which children's BSF-R scores are regressed on EXEMPT, and columns (4) and (5) show the IV estimates on both maternal employment measures. Panel A provides these results for the welfare-eligible subsample, and, as a robustness check, Panel B provides them for the ineligible subsample. All models include the full set of controls, and the standard errors are adjusted for clustering within date of assessment cells.

Looking at the OLS results in Panel A, the evidence consistently points to a positive relationship between early maternal employment and children's cognitive ability test scores. The coefficient on WORK in column (1) implies that any maternal employment since childbirth is associated with a 0.6 percent increase in BSF-R scores at the 9-month assessment, while the coefficient in column (2) implies that an additional month of work increases test scores by 0.06 percent. Both estimates are highly statistically significant. Turning to the OLS results for the ineligible subsample, shown in Panel B, it appears that early maternal does not influence the test scores of economically advantaged children. The magnitudes of both coefficients are smaller than their counterparts in Panel A, and neither coefficient is statistically significant.

The reduced form estimate in Panel A is negative, indicating that reductions in the AYCE time allotment are associated with lower test scores. Specifically, a one-month reduction in the AYCE allotment reduces BSF-R scores by 0.04 percent. This result is interesting in its own right because it illustrates the relationship between an important public policy lever-exemptions from parental welfare work requirements-and child ability. This can be interpreted as an intent-to-treat estimate of AYCEs, in that it averages the effect of work requirement exemptions over mothers who did and did not change their work behavior because of the exemption. At least one previous study attempts to estimate this reduced form relationship, and finds that such AYCEs are not related to child outcomes (Washbrook et al., 2011). The falsification test, shown in Panel B, indicates that, as expected, AYCEs are not associated with the BSF-R scores of children in non-welfare-eligible fami- 
lies. In fact, the coefficient on EXEMPT is half as large as and takes the opposite sign from that based on welfare-eligible subsample.

The remaining columns in Table 4 provide the baseline IV estimates of the impact of early maternal employment. These estimates are interpreted as the local average treatment effect (LATE) of maternal employment, because it reveals the effect of employment on the subset of mothers who altered their work behavior in response to the work requirement exemption. Given the positive coefficient on EXEMPT in the first-stage equation and its negative coefficient in the reduced form equation, it is not surprising that Panel A's IV estimates on WORK are negative. Looking at column (4), the coefficient suggests that any maternal work since childbirth reduces BSF-R scores by 6.8 percent. The IV estimate on cumulative months of maternal work is also negative, implying that an additional month of work lowers test scores by one percent. This corresponds to an effect size of 0.08 standard deviations $(S D s)$ per month of work.

The results in Panel B-based on a sample of families ineligible for welfare-provide evidence in favor of the validity of the identification strategy. In particular, the coefficient on EXEMPT in the reduced form equation [column (3)] takes the opposite sign from its counterpart in Panel A and is not statistically significant. Given the lack of explanatory power on EXEMPT in the first-stage equation, one might expect the IV estimates on WORK to be statistically insignificant. As shown in columns (4) and (5), the IV standard errors are substantially larger than their counterparts in Panel A, leading to highly imprecise estimates. In addition, the coefficients take the opposite sign compared to those based on the welfare-eligible subsample.

\section{Robustness}

Table 6 provides an additional set of specification checks. ${ }^{23}$ Rows (1) through (3) test the sensitivity of the baseline IV estimates to the omission of groups of control variables. This exercise further assesses the validity of EXEMPT as an instrument: if EXEMPT generates exogenous changes in maternal employment, then the IV estimates on any maternal work and cumulative work should not be highly sensitive to the exclusion of basic demographic controls. Row (1) omits the full set of family controls (except birth-order), row (2) omits the full set of child controls (except child's age and agesquared), and row (3) omits both sets of controls. The point estimates on WORK are consistently similar to the baseline estimates, but the standard errors tend to be larger. This indicates that the

\footnotetext{
${ }^{23}$ In an additional robustness check not discussed in the text, I estimate IV models that cluster the standard errors in stateof-birth cells rather than date-of-assessment cells. The coefficients on both measures of WORK remain statistically significant at the 10 percent level. The standard error on the binary indicator of any work increases somewhat, while the standard error on cumulative work declines slightly.
} 
observable covariates are important not to maintain the exogeneity of EXEMPT, but instead to increase the efficiency of the IV estimates. Such results provide additional support for the validity of the IV strategy.

The next four rows [rows (4) through (6)] experiment with richer sets of maternal characteristics. As previously stated, the baseline model includes a dummy variable for families residing in states with more generous parental leave provisions than the FMLA. This control allays concerns over the possibility that states' AYCEs are correlated with other parental leave policies. As a further check, I use an ECLS-B item that asks mothers about leave-taking in the months following the child's birth. Specifically, row (4) includes a dummy variable that equals unity for mothers taking paid or unpaid job leave during pregnancy or after the child was born. Another concern is that WORK, which measures post-birth employment activity, might be correlated with pre-birth employment, thus biasing the IV estimates on WORK if pre-birth employment influences child ability. Therefore, row (5) adds a dummy variable that equals unity for mothers who did any paid work in the year prior to childbirth. Row (6) includes four additional maternal background controls: separate dummy variables for whether the mother lived with the biological mother and father until age 16 and separate dummy variables for whether the mother's biological mother and father were high school drop-outs. Accounting for these maternal characteristics does not change the baseline IV estimates.

It was shown earlier that EXEMPT is associated not just with increased work participation but also with reductions in TANF participation. In other words, a reduction in the time remaining in mothers' exemption from the work requirement increases the attractiveness of employment while decreasing the attractiveness of welfare receipt. The loss of welfare income is therefore one potential explanation for the negative IV estimates on WORK. I test this possibility by including a variable capturing the number of months a given family received TANF since childbirth. As shown in row (7), the IV estimates are similar in magnitude to the baseline estimates, suggesting that workrequirement-induced changes in welfare participation are not driving the negative effect of early maternal work.

In addition to granting child-age exemptions from the work requirements, states may exempt women for a variety of other reasons. Key exemption categories include women caring for an ill or incapacitated family member (exempt in 34 states) and women who are pregnant (exempt in 20 states). It is plausible that state decision-making regarding the generosity of AYCE allotments is 
correlated with decisions on whether to exempt other categories of women. Thus, it may be important to incorporate controls for these additional work requirement exemptions. The estimates in row (8) are from a model that includes separate dummy variables denoting state exemptions for women caring for an ill family member and for women who are pregnant. The IV estimates on WORK are similar to the baseline estimates; if anything the results imply somewhat larger negative effects of early maternal employment.

Recall that the baseline estimates are generated from a sample of children born to mothers with less than a college degree or who are unmarried. As previously stated, the welfare reform literature is unsettled as to the most appropriate maternal characteristics for identifying welfare-eligible households. Therefore, results in the next two rows come from models that alter the definition of the analysis sample. Row (9) removes the marital status criterion, so that educational attainment is the sole maternal characteristic for delineating the sample. At least one previous welfare reform study uses education exclusively, perhaps because of concerns over sample selection biases introduced by using marital status as a criterion (Schoeni \& Blank, 2000). The IV results based on this alternative sample definition are similar to the baseline estimates. Row (10) establishes more narrow criteria for defining welfare-eligible households. In particular, the sample includes children born to mothers with no more than a high school degree and who are unmarried. The point estimates are similar to the baselines estimates, although neither is statistically significant because the standard errors are substantially larger. One reason for this is that the narrower definition reduces the sample size by about two-thirds relative to the baseline sample. ${ }^{24}$

The final robustness check, shown in row (11), tests an alternative version of the instrument. Rather than calculate the AYCE allotment in relation to the focal child's age, as is done in the baseline model, the alternative instrument assigns an allotment to each family based on the child's state of birth and birth-order. One can think of this measure as capturing welfare-eligible mothers' maximum AYCE allotment at the time the focal child is born. It is distinct from the baseline instrument in that it does not convey the amount of exempt time remaining at the time the focal child is assessed. The median on this alternative instrument is four months, with a range of zero to 24 months. The first-stage F-statistics are 28.4 and 21.7 for the any work and cumulative work outcomes, re-

\footnotetext{
${ }^{24}$ In an additional robustness check not discussed in the text, I alter the sample by removing children born in Oklahoma, Washington, and Wyoming, i.e., the states granting lifetime AYCE allotments. The aim here is to test the sensitivity of the estimates to the assumption that women take maximum allowable AYCE for each child. Recall that in constructing $E X$ $E M P T$, I assign the maximum AYCE allotment to women residing in these states. The IV estimates are similar to those reported in the text.
} 
spectively. As shown in row (9), the IV estimates are similar in magnitude to the baseline estimates, although the impact of cumulative work is no longer statistically significant.

\section{Timing of the Maternal Return to Work}

The results presented to this point suggest that work requirement-induced entries into employment during the first year of life have negative effects on children's cognitive development. It is possible that heterogeneity exists according to the timing of the return to work within the first year. Previous research finds that timing does indeed matter, with earlier returns having larger negative effects than later returns, although some of this work compares first-year employment with that occurring in the second and third years of life (e.g., Ruhm, 2004). Han, Waldfogel, and Brooks-Gunn (2001) examine heterogeneity within the first year by comparing the developmental implications of beginning work within the first three quarters after childbirth versus beginning work in the fourth quarter. Here again the authors find larger negative effects of earlier returns to work.

I examine heterogeneity throughout the first year of life by using EXEMPT to instrument for a series of dummy variables indicating the age (of the child) at which the mother began working. Specifically, I construct 11 binary indicators for whether the mother was employed within the first two months after childbirth, within the first three months after childbirth, and so on up to 12 months. I then estimate separate IV models using EXEMPT as an instrument for each month-ofwork indicator. Results from this analysis are summarized in Figure 6, which plots the IV coefficient from each month-of-work model along with the upper and lower bounds of the 90 percent confidence interval. $^{25}$

A few observations are noteworthy. First, maternal returns to work-no matter when they occur during the first year of life-have negative effects on children's early cognitive development. All of the month-of-work indicators are negatively signed, and all but one are statistically significant at the 10 percent level. Nevertheless, there is substantial variation in the estimates, ranging from a 20 percent reduction in BSF-R scores (for children of mothers who worked within two months) to a 6.7 percent reduction in scores (for children of mothers who worked within 11 months). In addition, consistent with previous work, later returns to work generate smaller reductions in test scores, but only up to a point. The magnitude of the (negative) test score effect declines in each subsequent month-

${ }^{25}$ This analysis begins with returns to work at two months because relatively few mothers began working at zero months (3.5 percent of the sample) or within one month (13.9 percent of the sample). Within the first two months of life, on the other hand, 26 percent of mothers had begun working. In addition, the first-stage estimates on EXEMPT are statistically insignificant in the models for months zero and one, leading to implausibly large second-stage estimates of maternal work. For the remaining month-of-work indicators (i.e., months two through 12), the first-stage estimate on EXEMPT is statistically significant and positively signed. 
of-entry until about the eighth month of life, after which the negative effects stabilize. Indeed, starting work at some point in the fourth quarter of life produces substantially smaller and more stable test score effects than doing so in the first or second quarters of life.

\section{Sub-Group Analyses}

In results not presented in the tables, I estimate the baseline IV model on a number of sub-groups defined by the focal child's gender, race and ethnicity, and low birth weight status as well as the mother's pre-birth employment status. All of the sub-group analyses are estimated using the binary indicator of any post-birth maternal work and the continuous measure of cumulative months of work. Previous research is mixed on whether early maternal employment has larger negative effects on boys or girls. Some studies find larger effects on boys (e.g., Desai, et al., 1989; Brooks-Gunn, et al., 2002), others on girls (e.g., Bernal \& Keane, 2011; Waldfogel, et al., 2002), and still others find no differences (e.g., Ruhm, 2004). I find little evidence that disadvantaged boys and girls are differentially affected by early maternal employment. Although any work as of the 9-month assessment is predicted to lower BSF-R scores of girls by more than boys (6.4 versus 5.6 percent test score reduction, respectively), the opposite holds for the measure of cumulative work ( 0.7 versus 1.0 percent, respectively). None of the individual IV coefficients are statistically significant, and neither are the tests of boy-girl differences in the IV estimates.

Next, I examine test score effects across non-minority (i.e., white) and minority (i.e., black and Hispanic) children. Again, the literature yields mixed results, with some studies finding larger negative effects on white children (e.g. Bernal \& Keane, 2011; Han, et al., 2001; Waldfogel, et al., 2002) and others finding no systematic differences (e.g., Ruhm, 2004). This analysis finds meaningful differences across non-minority and minority children. Any maternal work is predicted to reduce BSF-R scores of white children by 14.4 percent, compared to a decrease of 4.2 percent among black and Hispanic children. The comparable estimates for cumulative work are 1.9 percent for whites and 0.6 percent for blacks and Hispanics. Both white IV coefficients are statistically significant, as are the tests of non-minority-minority differences.

I also examine whether severely disadvantaged children are more sensitive to early maternal work, using children's low birth weight status as a proxy for disadvantage. As previously stated, low birth weight babies have worse outcomes in the short- and long-run (e.g., Black et al., 2007; Case et al., 2004). Therefore, it is important to determine whether post-birth conditions such as early maternal employment exacerbate or mitigate those outcomes. The IV estimates indicate that maternal 
work may exacerbate the early disadvantages associated with low birth weight. For example, any work since childbirth is estimated to lower BSF-R scores by 24.1 percent among low birth weight children, compared to a 3.2 percent reduction among normal weight children. IV estimates based on the measure of cumulative work imply similarly large differences, with low birth weight children experiencing a test score drop of 2.9 percent for each month of work, while normal weight children experience a reduction of 0.5 percent. Both low birth weight IV coefficients are statistically significant, as are the tests of birth weight differences.

In the final set of sub-group analyses, I examine whether mothers' pre-birth employment status has implications for the impact of post-birth employment on child ability. It is possible that disadvantaged women with pre-birth work experience sustain fewer family disruptions and find it easier to transition back into the labor market than their counterparts with less (or with less recent) prebirth work experience. For the purposes of this research, pre-birth work experience is defined as having worked at all in the year prior to giving birth. The IV results are suggestive of such a pattern. The impact of early maternal work is consistently associated with larger negative test score effects for children whose mothers did not work: such children experience test score reductions of 11.2 (any work) and 2.4 (cumulative work) percent, compared to 7.4 and 1.0 percent among children whose mothers did work prior to giving birth.

\section{Mechanisms}

The results discussed to this point suggest that work-requirement-induced increases in early maternal employment have deleterious effects on disadvantaged children's short-run cognitive development. There are a number of mechanisms through which such an employment effect may influence child ability. The models presented in Table 7 provide a detailed assessment of several potential mechanisms organized around family income and material resources [row (1)], maternal health [rows (2) through (4)], parent-child interactions and parental time investments [rows (5) through (8)], and participation in non-parental child care [rows (9) through (11)]. Data on these mechanisms come from the 9-month survey. Column (1) presents the mean on each measure. Refer to the notes at the

bottom of Table 7 for a description of how each measure is constructed. Column (2) presents the reduced form estimate on EXEMPT, while columns (3) and (4) present the IV estimates on WORK (i.e., the binary indicator of any work and the measure of cumulative months of work). The mechanism analyses are performed on the subsample of welfare-eligible families. All models include the full set of covariates described previously. 
A number of recent studies find that family income is strongly related to early and later child development (e.g., Blau, 1999; Dahl \& Lochner, 2012; Loken et al., 2010; Milligan \& Stabile, 2011). Increases in family income likely improve parental and child physical and mental health, and enable parents to invest in goods and services that promote child ability. Thus, the first mechanism relates to family income. Although the ECLS-B does not contain a high-quality measure of family income or maternal earnings, the survey provides an indicator denoting whether family income is below the Federal Poverty Line (FPL). As shown in row (1), a large fraction of welfare-eligible children reside in poor families (33 percent). Nevertheless, the reduced form estimate on EXEMPT implies that reductions in the AYCE time allotment is associated with lower poverty rates. This finding is consistent with the IV results, in which work-requirement-induced increases in maternal employment decrease the likelihood of falling below the FPL.

Although these results appear to be at odds with the negative test score effects, a few caveats should be kept in mind. First, it is possible that the income required to bring a family above the FPL is not sufficient to improve the child's cognitive ability. Second, the FPL measure is based on current rather than permanent income, with the latter shown to be more important to child ability. Finally, as will be shown, family income is the only mechanism that yields a result consistent with an improvement in child ability. In other words, early maternal employment may produce a sufficiently strong set of headwinds that cannot be overcome by improvements in families' material well-being.

The next set of rows [rows (2) through (4)] investigates mechanisms related to maternal health. It appears that early maternal work does not improve overall health, as shown in row (2), defined as self-reports of overall health as excellent or very good (as opposed to good, fair, or poor). Furthermore, the results in rows (3) and (4) suggest that maternal employment may increase depression symptomology, as measured by the 12-item Center for Epidemiologic Studies Depression (CESD) scale (Radloff, 1977). ${ }^{26}$ Maternal responses on the individual items are summed to produce the full CES-D scale. The sample mean is 5.6 , with a minimum value of zero and a maximum of 36 . The IV estimates on the full CES-D [row (3)] imply substantively meaningful, but imprecisely estimated, increases in depression symptomology. Row (4) recodes one of the items into a binary indicator that equals unity if a given mother felt depressed during one or more days throughout the previous week.

\footnotetext{
${ }^{26}$ Mothers were asked about the number of days in the previous week they (a) felt bothered by things that usually do not bother them, (b) experienced diminished appetite, (c) felt that they could not shake off the blues even with help from family members or friends, (d) felt depressed,(e) felt that everything they did was an effort, (f) felt fearful, (g) slept restlessly, (h) talked less than usual, (i) felt lonely, (j) felt sad, (k) felt unable to get going, (l) could not keep the mind focused. Responses on each item were recoded to conform to the scale's original construction: zero (less than one day), one (one to two days), two (three to four days), and three (five to seven days).
} 
Here, the IV estimates indicate that early maternal work leads to statistically significant increases in depressive symptoms.

The next four analyses, depicted in rows (5) through (8), relate to various features of the mother-child relationship as well as the quality of maternal time inputs. Row (5) examines whether work-requirement-induced increases in maternal employment have implications for breast-feeding. A large literature finds that breast-feeding is associated with numerous short- and long-run physiological, health, and cognitive benefits (e.g., Horwood \& Fergusson, 1998; Lawrence, 2000). Previous studies also find that early maternal employment can disrupt breast-feeding practices (Lindberg, 1996), and at least one study indicates that welfare reform lowered rates of breast-feeding among disadvantaged mothers (Haider et al., 2003). The reduced form and IV results, which show substantial reductions in breast-feeding, are consistent with this evidence. Row (6) examines maternal scores on the Nursing Child Assessment Teaching Scale (NCATS), a 50-item measure of various domains of parent-child interactions, including maternal responsiveness and cognitive and social-emotional growth fostering. ${ }^{27}$ The number of positive maternal behaviors is summed over the 50 items to produce the full NCATS score. The sample mean is 33.8 , with a minimum score of 15 and a maximum of 48 . The IV estimates in row (6) are small in magnitude and statistically insignificant. Row (7) explores maternal views regarding the child's temperament and attachment. In particular, I create a binary indicator that equals unity if a given mother reports that the child "demands attention and company constantly" and "needs a lot of help to fall asleep." 28 The results consistently suggest that working mothers are more likely to respond affirmatively to these statements. Finally, row (8) examines the frequency with which mothers read to the child. I create a binary indicator that equals unity if a family member reads to the child at least one time per week. The estimates indicate that maternal employment reduces the likelihood that the focal child is read to on a consistent basis.

The final set of analyses, shown in rows (9) through (11), examine the extent to which maternal employment influences the use of non-parental child care. Approximately one-half of ECLS-B infants participate in non-parental arrangements (as of the 9-month survey), and they do so for 33

\footnotetext{
${ }^{27}$ During the 9-month assessment, the mother was asked to select an NCATS task that the focal child had not yet been taught by the mother (or father). The mother was then asked to teach the child how to complete the task, and the interaction was videotaped. Four primary dimensions of the interaction were coded to produce the parent NCATS score: responsiveness of the parent to the child's cues, cognitive growth fostering, socio-emotional growth fostering, and responsiveness to the child's distress. Each of the 50 items is coded on a yes/no basis: if a given maternal behavior occurs, the item is coded "yes." If the behavior does not occur, the item is coded "no." The total parent score is calculated by summing the number of "yes" responses over the 50 items.

${ }_{28}$ These are separate questionnaire items in the 9-month survey. Mothers are coded a value of one if they report that the child "sometimes" or "most times" behaves in this manner on both items. Mothers are coded a value of zero if they report "never" or "used to be."
} 
hours per week (Herbst, 2013b). There is a large literature in economics and developmental psychology studying the relationship between non-parental child care and short-run outcomes. Although the literature is mixed overall, a few recent studies provide causal evidence that early child care utilization lowers cognitive ability test scores among disadvantaged children (Bernal \& Keane, 2011; Herbst, 2013b). Results in rows (9) through (11) indicate that the infants of employed mothers participate in non-parental care earlier than their non-working counterparts, and they participate in this care more intensively. In particular, such children are more likely to have started their first child care spell within the first three months of life. As of the 9-month assessment, children of working mothers accrue more months in non-parental arrangements, and they spend considerably more hours per week in those settings.

In sum, the results presented in Table 7 suggest that several factors may explain the negative effects of early maternal employment. Although working mothers experience improved material wellbeing-defined as lower poverty rates-they do not appear to be in better health, and there is suggestive evidence of increased depressive symptoms. Furthermore, children of working mothers are less likely to be breast fed, and there is a drop in the quality of mother-child interactions, defined as a reduction in the frequency that family members read to the child. Working mothers also report increased behavioral difficulties with the child, including persistent demands for attention and requiring assistance to fall asleep. Finally, children of working mothers are more likely to experience nonparental child care early in life: they are exposed to their first non-parental arrangement at a younger age, and spend more time in these settings throughout the first year of life.

\section{Conclusion}

The aim of this paper is to provide causal evidence on the impact of early maternal employment on young children's cognitive development. It studies this issue within the context of a highly policyrelevant population-economically disadvantaged mothers and their children-and uses a policy lever of considerable interest-exemptions from the welfare work requirements-to derive the instrumental variables estimates. Indeed, the local average treatment effects (LATE) estimated here have potentially important policy implications because they reflect the impact of a fundamental economic behavior-maternal labor supply following child birth-whose impact on child ability is derived from one of the most provocative social policy reforms of the past several decades.

Using a nationally representative sample of infants from the ECLS-B, I find that AYCEs from the welfare work requirements are strongly correlated with first-year maternal employment. 
Specifically, reductions in the AYCE time allotment are predicted to increase the rate and intensity of employment in the first year after childbirth. Results from OLS estimation of the child ability production function suggest that children of working mothers score higher on the BSF-R than their counterparts whose mothers did not work since childbirth. However, the IV results suggest that the OLS estimates are severely biased upward. When AYCE allotments are used to instrument for early maternal work, I find that BSF-R scores are lower among children of working mothers. Each month of work is estimated to lower cognitive ability test scores by $0.08 S D$ s.

This paper also illuminates some the mechanisms through which the negative employment effects likely operate. Although families with working mothers are less likely to be poor, it appears that the improvement in material well-being is insufficient to fully offset the many challenges catalyzed by early maternal work. Working mothers are not in better overall health than their nonworking counterparts, and there is suggestive evidence that they experience an increase in depressive symptoms. Furthermore, children of working mothers are less likely to be breast fed, and they are read to less frequently. Working mothers report increased behavioral complications with the child, including demands for attention and difficulties falling asleep. Finally, children of working mothers are exposed non-parental child care arrangements at a younger age, and they spend more time in these settings throughout the first year of life.

This paper's first-stage employment results are consistent with those in Hill (2012) and Washbrook et al., (2011), which find that exposure to more generous AYCE allotments are associated with reductions in employment rates among disadvantaged mothers. The only other study to examine the developmental impact of AYCEs is Washbrook et al., (2011), who provide reduced form estimates that imply neutral effects on a wide range of intermediate and direct measures of child well-being. Nevertheless, the IV results in this paper are consistent with previous welfare reform studies finding reductions in breast feeding rates (Haider et al., 2003) as well as declines in prenatal care and increases in the incidence of low birth weight (Kaestner \& Lee, 2005). The results are also consistent with the IV estimates presented in Bernal and Keane (2011), who use a variety of prePRWORA social policies as instruments to identify the impact of maternal employment and child care use on disadvantaged children's cognitive development. Finally, it is worth noting that results in this paper are consistent with those in Herbst and Tekin's (2010a; 2010b; 2014) evaluation of the U.S.'s Child Care and Development Fund (CCDF), a means-tested child care subsidy program. Alt- 
hough subsidy receipt has large positive effects on maternal employment, the program has detrimental effects on children's cognitive and behavioral development as well as maternal health.

The results in this paper highlight an unintended consequence of the U.S.'s movement to a work-based social safety net. The 1996 PRWORA is but one in a series of policy reforms starting in the late-1980s and continuing into the 2000s that condition eligibility for public benefits on maintaining some attachment to the labor market. Indeed, the 1996 welfare reform law, which included strict work requirements and time limits, along with its companion child care subsidy program (the $\mathrm{CCDF}$ ), was viewed as an effective approach for dealing with the "problem" of low employment rates among disadvantaged mothers. It has become clear since the passage of welfare reform that policies such as work requirements, time limits, and child care subsidies are effective policy levers for increasing employment. However, the success of welfare and related policy reforms must be evaluated not just against the benefits of increased maternal employment, but also the costs associated with reduced child well-being. Such considerations are particularly salient in light of recent policy proposals to bring work requirements to other programs within the safety net (e.g., U.S. House Budget Committee, 2014). 


\section{References}

Anderson, P. M., Butcher, K. F., \& Levine, P. B. (2003). Maternal employment and overweight children. Journal of Health Economics, 22, 477-504.

Baker, M. \& Milligan, K. (2008). Maternal employment, breastfeeding, and health: Evidence from maternity leave mandates. Journal of Health Economics, 27,871-887.

Baker, M. \& Milligan, K. (2010). Evidence from maternity leave expansions of the impact of maternal care on early child development. Journal of Human Resources, 45, 1-32.

Baker, M. \& Milligan, K. (2011). Maternity leave and children's cognitive and behavioral development. NBER Working Paper No. 171055. Cambridge, MA: National Bureau of Economic Research.

Bernal, R. \& Keane, M. (2011). Child care choices and children's cognitive achievement: The case of single mothers. Journal of Labor Economics, 29, 459 - 512.

Bernal, R. (2008). The Effect of Maternal Employment and Child Care on Children's Cognitive Development. International Economic Review, 49, 1173-1209.

Bitler, M. P., Gelbach, J. B., Hoynes, H. W., \& Zavodny, M. (2004). The impact of welfare reform on marriage and divorce. Demography, 41, 213-236.

Bitler, M., Gelbach, J. \& Hoynes, H. (2005). Welfare reform and health. Journal of Human Resources, 40, 309-334.

Bitler, M., Gelbach, J. \& Hoynes, H. (2006). Welfare reform and children's living arrangements. Journal of Human Resources, 41, 1-27.

Black, S., Devereux, P., \& Salvanes, K. (2005). The more the merrier? The effect of family size and birth order on children's education. Quarterly Journal of Economics, May, 669-700.

Black, S., Devereux, P., \& Salvanes, K. (2007). From the cradle to the labor market? The effect of birth weight on adult outcomes. Quarterly Journal of Economics, February, 409-439.

Blau, D. M. (1999). The effect of income on child development. Review of Economics and Statistics, 81, 261-276.

Brooks-Gunn, J., Han, W.-J., \& Waldfogel, J. (2002). Maternal Employment and Child Cognitive Outcomes in the First Three Years of Life: The NICHD Study of Early Child Care. Child Development, 73, 1052-1072.

Buckles, K. \& Hungerman, D. (2010). Season of birth and later outcomes: Old questions, new answers. NBER Working Paper No. 14573. Cambridge, MA: National Bureau of Economic Research.

Case, A., Fertig, A., \& Paxson, C. (2004). The lasting impact of childhood health and circumstance. Journal of Health Economics, 24,365-389.

Chase-Lansdale, P.L., Moffitt, R., Lohman, B., Cherlin, A., Coley, R., Pittman, L., Roff, J., Votruba \& Drzal, E. (2003). Mothers' transitions from welfare to work and the well-being of preschoolers and adolescents. Science, 299, 1548-1552.

Corman, H., Dave. D. M., Reichman, N. E., \& Das, D. (2010). Effects of welfare reform on illicit drug use of adult women. NBER Working Paper No. 16072. Cambridge, MA: National Bureau of Economic Research.

Dahl, G. \& Lochner, L. (2012). The Impact of Family Income on Child Achievement: Evidence from the Earned Income Tax Credit. American Economic Review, 102, 1927-1956.

Dahl, G., Loken, K., Mogstad, M., \& Salvanes, K. (2013). What is the case for paid maternity leave? NBER Working Paper No. 19595. Cambridge, MA: National Bureau of Economic Research. 
Desai, S., Chase-Lansdale, P. L., \& Michael, R. T. (1989). Mother or market? Effects of maternal employment on the intellectual ability of 4-year-old children. Demography, 26, 545-561.

Dustmann, C. \& Schoneberg, U. (2012). The effect of expansions in maternity leave coverage on children's long-term outcomes. American Economic Journal: Applied Economics, 4, 190-224.

Fang, H. \& Keane, M. (2004). Assessing the impact of welfare reform on single mothers. Brookings Papers on Economic Activity, 35, 1-116.

Grogger, J. (2003). The effects of time limits, the EITC, and other policy changes on welfare use, work, and income among female-headed families. Review of Economics and Statistics, 85, 394-408.

Grogger, J. \& Karoly, L. (2005). Welfare reform: Effects of a decade of change. Cambridge, MA: Harvard University Press.

Haider, S., Jacknowitz, A., \& Schoeni, R. (2003). Welfare work requirements and child well-being: Evidence from the effects of breast-feeding. Demography, 40, 479-497.

Han, W. J., Waldfogel, J., \& Brooks-Gunn, J. (2001). The effects of early maternal employment on later cognitive and behavioral outcomes. Journal of Marriage and Family, 63, 336-354.

Herbst, C.M. (2012). Footloose and fancy free? Two decades of single mothers' subjective well-being. Social Service Review, 86, 189-222.

Herbst, C.M. (2013a). Welfare reform and the subjective well-being of single mothers. Journal of Population Economics, 26, 203-238.

Herbst, C.M. (2013b). The impact of non-parental child care on child development: Evidence from the summer participation "dip." Journal of Public Economics, 105, 86-105.

Herbst, C. M., \& Tekin, E. (2010a). Child care subsidies and child development. Economics of Education Review, 29, 618-638.

Herbst, C. M., \& Tekin, E. (2010b). The impact of child care subsidies on child well-being: Evidence from geographic variation in the distance to social service agencies. NBER Working Paper No. 16250. Cambridge, MA: National Bureau of Economic Research.

Herbst, C. M. \& Tekin, E. (2014). Child care subsidies, maternal health, and child-parent interactions: Evidence from three nationally representative datasets. Health Economics, 23, 894-916.

Hill, H. (2012). Welfare as maternity leave? Exemptions from welfare work requirements and maternal employment. Social Service Review, 86, 37-67.

Horwood, L. J., \& Fergusson, D. M. (1998). Breastfeeding and later cognitive and academic outcomes. Pediatrics, 101(1), e9-e9.

Ifcher J. (2011). The happiness of single mothers after welfare reform. B.E. Journal of Economic Analysis and Policy, 11.

James-Burdumy, S. (2005). The effect of maternal labor force participation on child development. Journal of Labor Economics, 23, 177-211.

Kaestner, R. \& Kaushal, N. (2003). Welfare reform and health insurance coverage of low-income families. Journal of Health Economics, 22, 959-981.

Kaestner, R. \& Lee W. (2005). The effect of welfare reform on prenatal care and birth weight. Health Economics, 14, 497-511.

Kaestner, R. \& Tarlov, E. (2006). Changes in the welfare caseload and the health of low-educated mothers. Journal of Policy Analysis and Management, 25, 623-643. 
Kaushal, N., \& Kaestner, R. (2005). Welfare reform and health insurance of immigrants. Health services research, 40, 697-722.

Kaushal, N., Gao, Q., \& Waldfogel, J. (2007). Welfare reform and family expenditures: How are single mothers adapting to the new welfare and work regime? Social Service Review, 81, 369-396.

Lawrence, R. A. (2000). Breastfeeding: benefits, risks and alternatives. Current Opinion in Obstetrics and Gynecology, 12(6), 519-524.

Lehmann, J. Y. K., Nuevo-Chiquero, A., \& Vidal-Fernández, M. (2012).Explaining the birth order effect: The role of prenatal and early childhood investments (No. 6755). Discussion Paper series, Institute for the Study of Labor.

Lindberg, L. D. (1996). Women's decisions about breastfeeding and maternal employment. Journal of Marriage and the Family, 58, 239-251.

Løken, K. V., Mogstad, M., \& Wiswall, M. (2010). What linear estimators miss: Re-examining the effects of family income on child outcomes. Discussion Paper No. 4971. Bonn, Germany: Institute for the Study of Labor.

Meyer, B. D. \& Sullivan, J. X. (2004). The effects of welfare and tax reform: the material well-being of single mothers in the 1980s and 1990s. Journal of Public Economics, 88, 1387-1420.

Meyer, B., Rosenbaum, D. (2001). Welfare, the Earned Income Tax Credit, and the labor supply of single mothers. Quarterly Journal of Economics, 116, 1063-1114.

Milligan, K. \& Stabile, M (2011). Do child tax benefits affect the well-being of children? Evidence from Canadian child benefit expansions. American Economic Journal: Economic Policy, 3, 175-205.

Monfardini, C., \& See, S. G. (2012). Birth order and child outcomes: Does maternal quality time matter? Discussion Paper No. 6825. Bonn, Germany: Institute for the Study of Labor.

Morrill, M. (2011). The effects of maternal employment no the health of school-age children. Journal of Health Economics, 30, 240-257.

Paxson, C., \& Waldfogel, J. (2003). Welfare reforms, family resources, and child maltreatment. Journal of Policy Analysis and Management, 22, 85-113.

Pingle, J. (2003). What if welfare had no work requirements? The age of youngest child exemption and the rise in employment of single mothers (Finance and Economics Discussion Series Working paper no. 2003-57). Washington, DC: Board of the Governors of the Federal Reserve System.

Radloff, L. S. (1977). The CES-D scale a self-report depression scale for research in the general population. Applied psychological measurement, 1(3), 385-401.

Rasmussen, A. (2010). Increasing the length of parents' birth-related leave: The effect on children's long-term educational outcomes. Labour Economics, 17, 91-100.

Rossin, M. (2011). The effects of maternity leave on children's birth and infant health outcomes in the United States. Journal of Health Economics, 30, 221-239.

Rote, S., \& Quadagno, J. (2011). Depression and alcohol dependence among poor women: Before and after welfare reform. Social Service Review, 85, 229-245.

Ruhm, C. (2004). Parental employment and child cognitive development. Journal of Human Resources, 39, 155-192.

Ruhm, C. (2008). Maternal employment and adolescent development. Labour Economics, 15, 958983. 
Schoeni, R. F., \& Blank, R. M. (2000). What has welfare reform accomplished? Impacts on welfare participation, employment, income, poverty, and family structure. NBER Working Paper No. 7627. Cambridge, MA: National Bureau of Economic Research.

U.S. Census Bureau. (2012). Statistical Abstract of the United States: 2012 (131st Edition). Washington, DC.

U.S. House Budget Committee. (2014). Expanding Opportunity in America: A Discussion Draft from the House Budget Committee. Washington, DC: U.S. House of Representatives, Committee on the Budget.

Urban Institute (2001). The Welfare Rules Database. Accessible at http://anfdata.urban.org/wrd/Query/query.cfm. Washington, DC: Urban Institute.

Waldfogel, J., Han, W.-J., \& Brooks-Gunn, J. (2002). The effects of early maternal employment on child cognitive development. Demography, 39, 369-392.

Washbrook, E., Ruhm, C., Waldfogel, J., \& Han, W-J. (2011). Public policies, women's employment after childbearing, and child well-being. B.E. Journal of Economic Analysis and Policy, 11. 
Figure 1: Maternal Employment in the First Year After Childbirth Source: Author's analysis of the 9-month wave of the ECLS-B

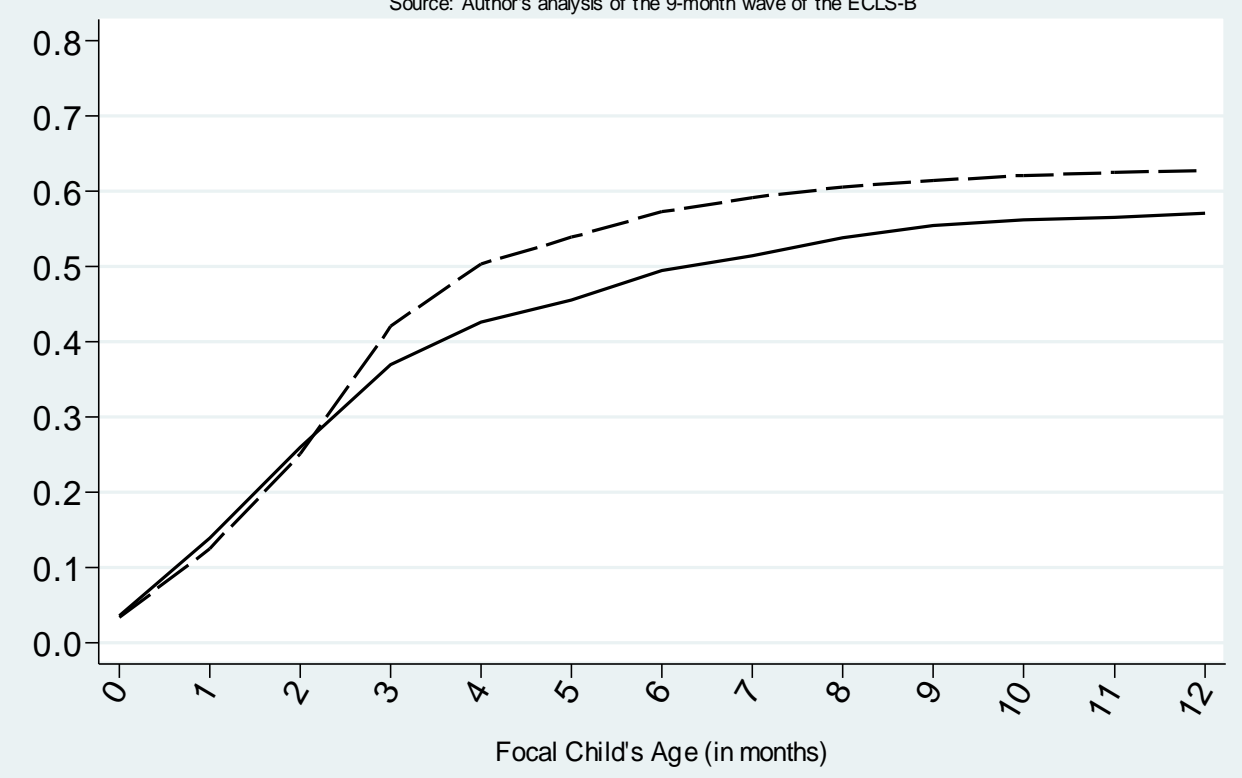

Welfare-eligible Mothers $\quad-\quad-$ Welfare-ineligible Mothers

Figure 2: Remaining AYCE Allotments for Welfare-Eligible Families, by State Top 15 states: TX to WV. Bottom 15 states: WA to ID

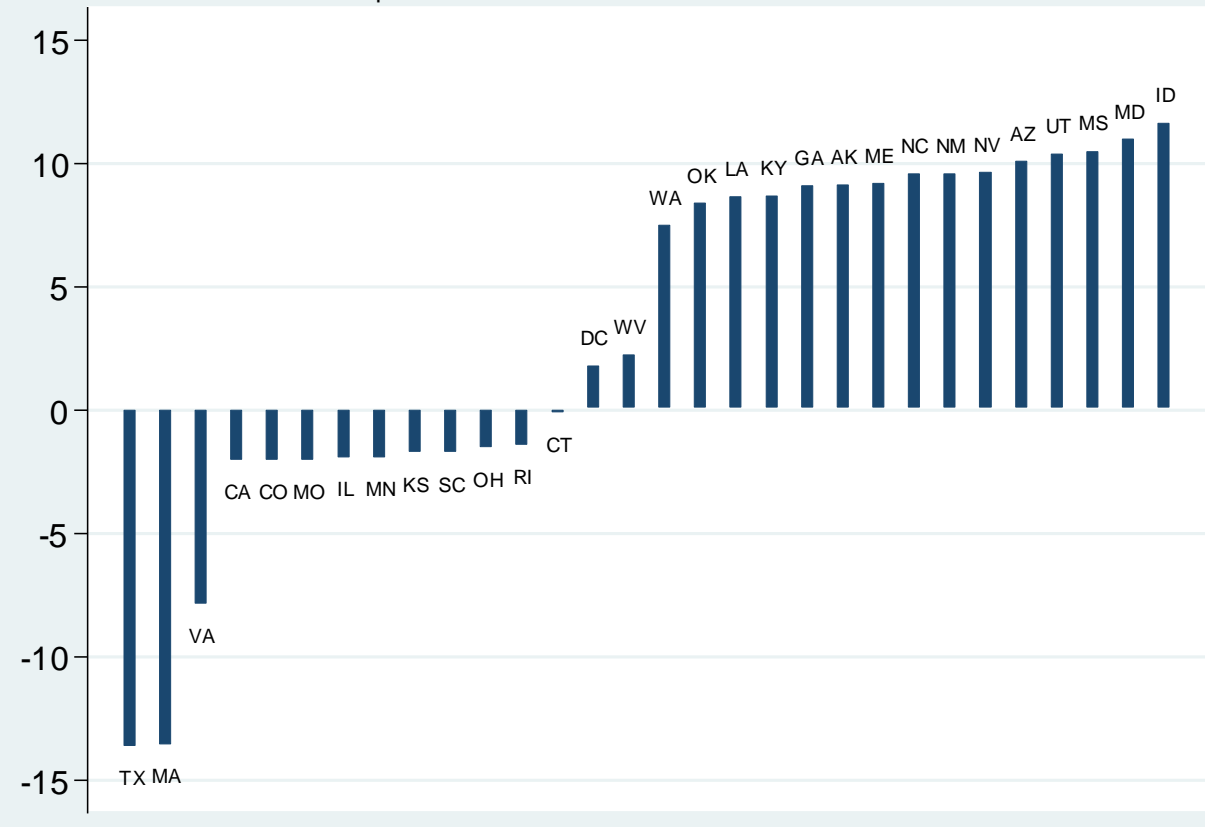


Figure 3a: Density Plot on the Instrumental Variable EXEMPT

Restricted to Families Exposed to AYCEs of Four Months or Less

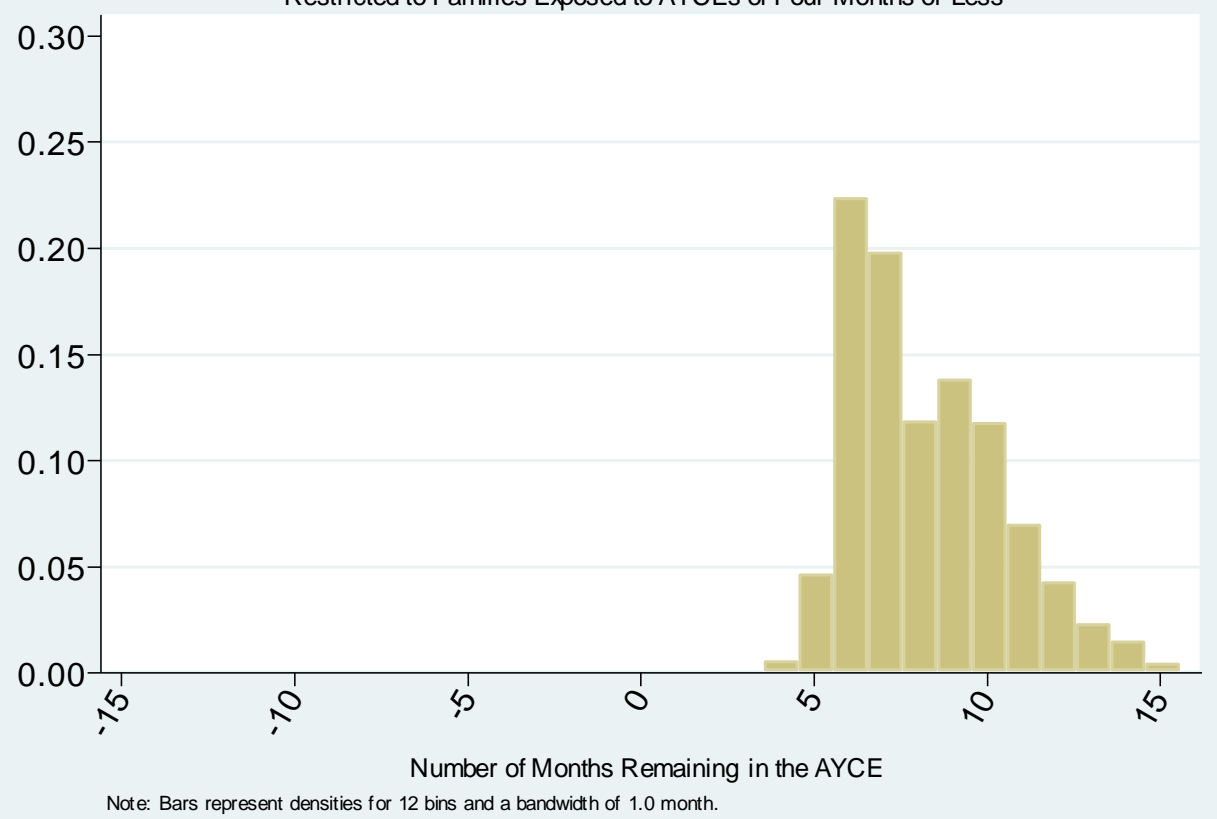

Figure 3b: Density Plot on the Instrumental Variable EXEMPT

Restricted to Families Exposed to AYCEs of More Than Four Months

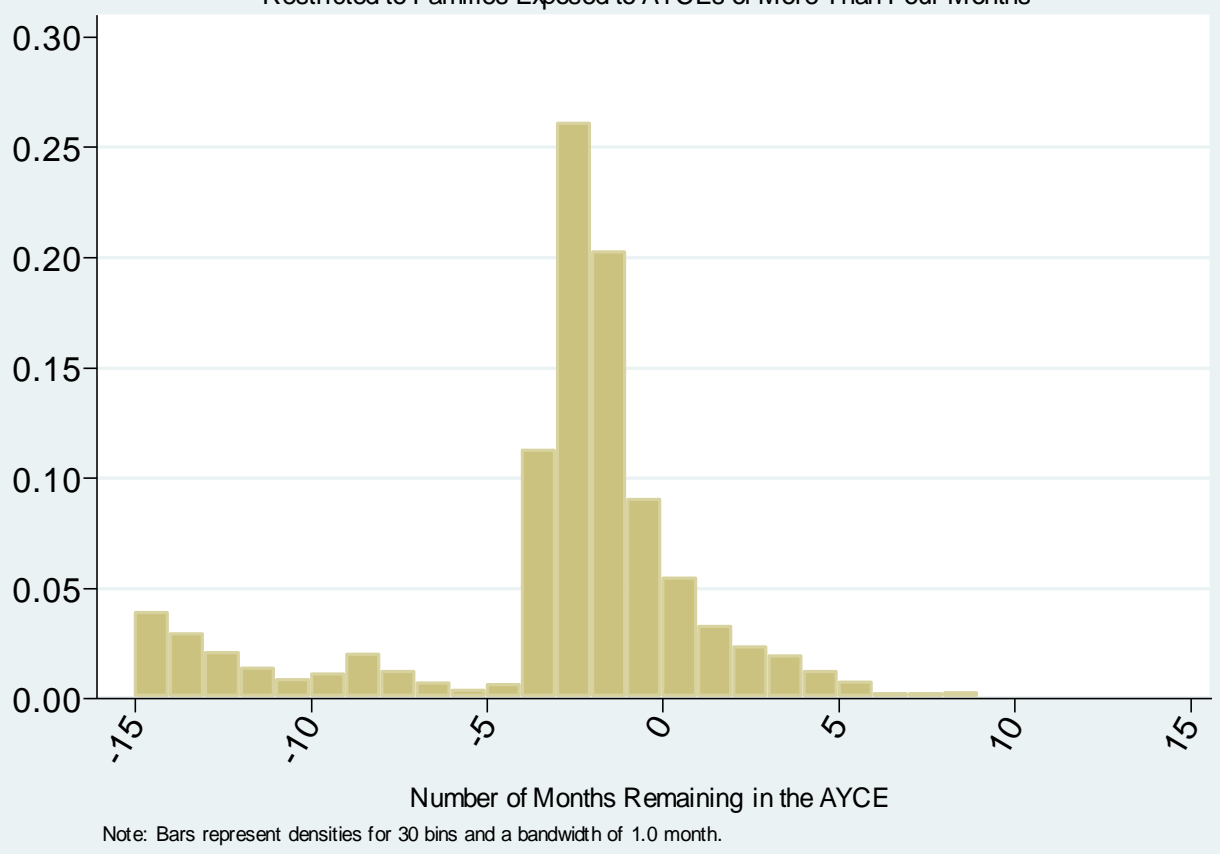



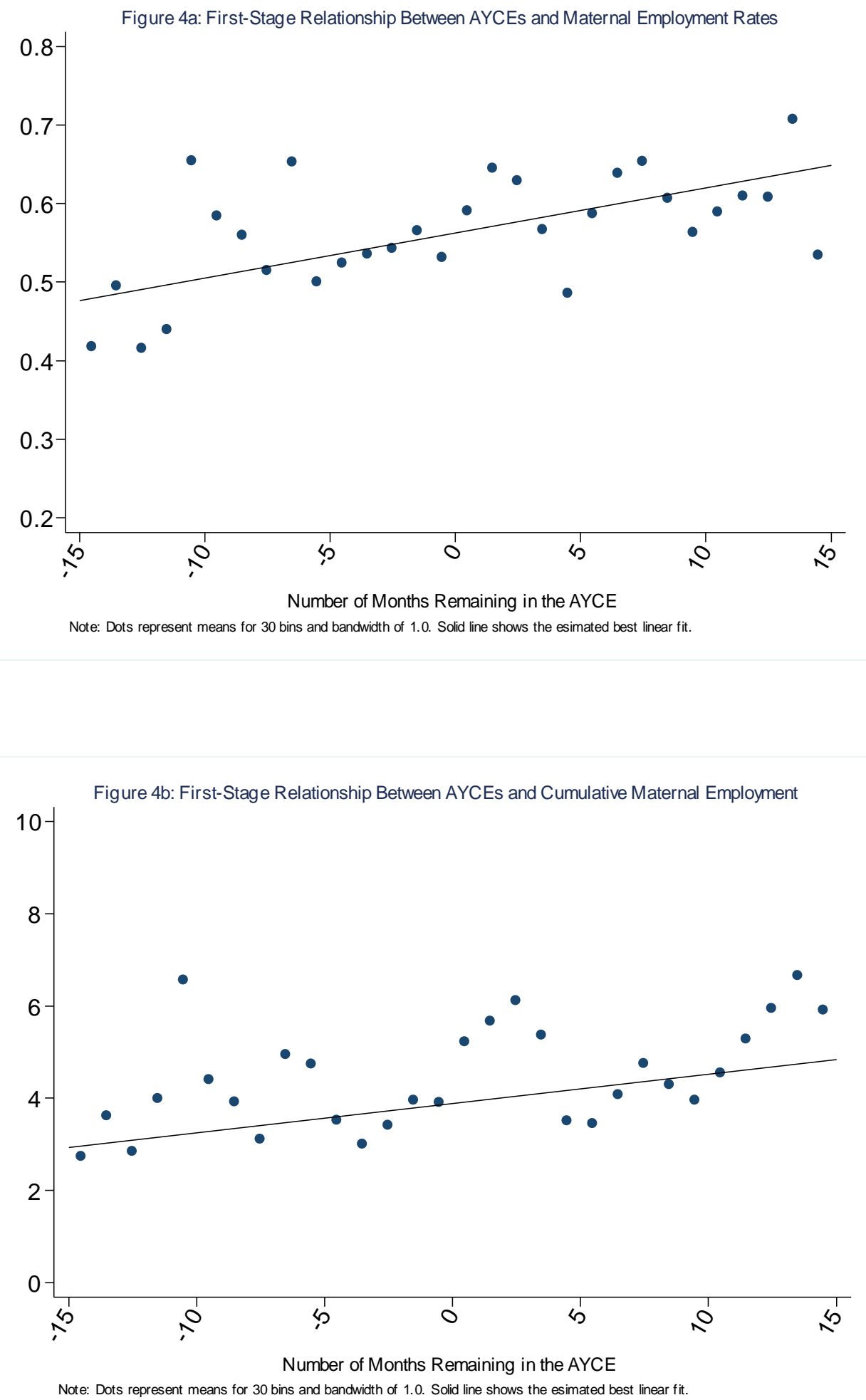

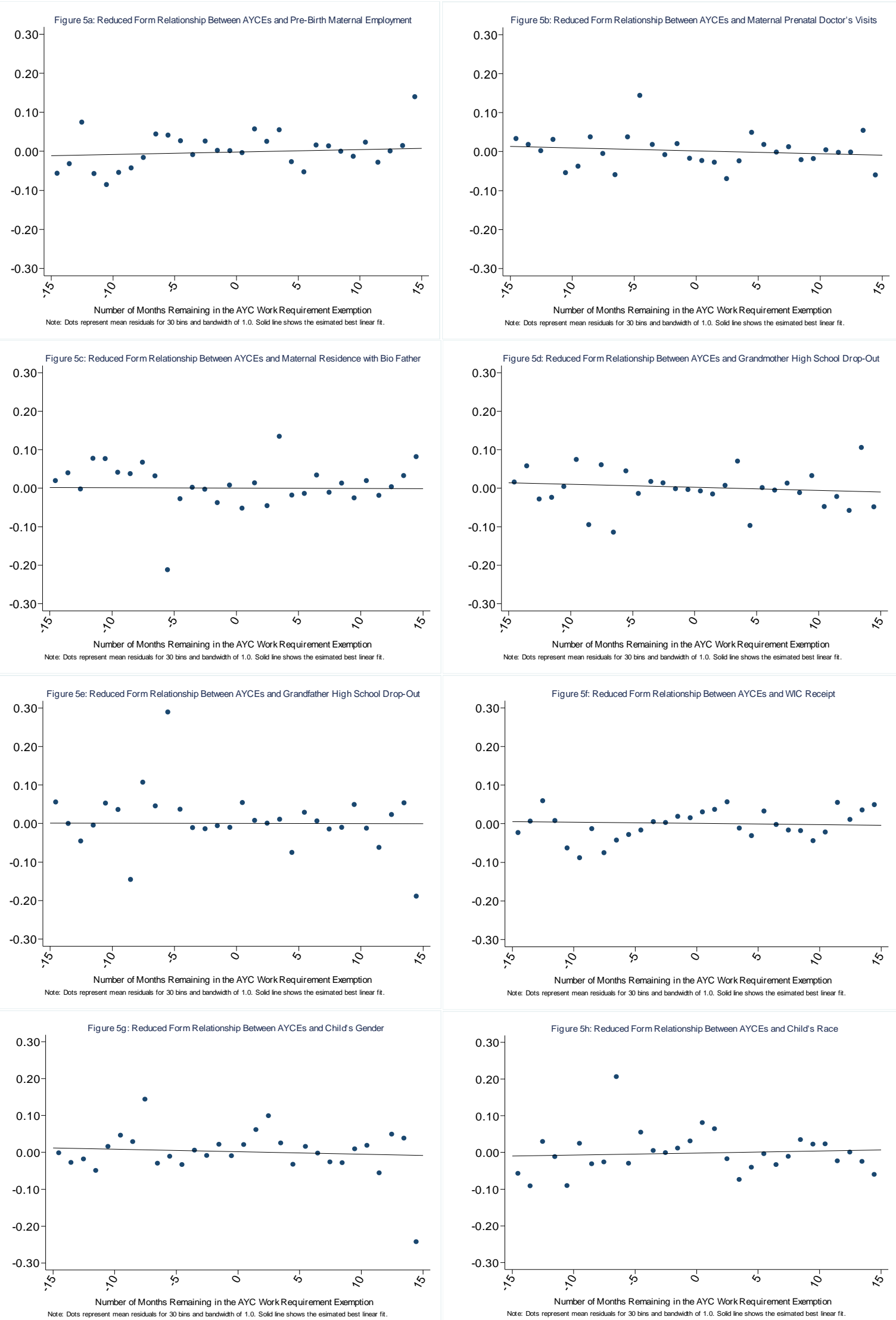
Figure 6: Instrumental Variables Estimates by Month of Maternal Return to Work

11 months -10 months 12 months -1 months

Note: Each estimate is generated by a different model. $90 \%$ confidence intervals are shown. 
Table 1: Summary of States' AYCE Provisions for 2001 (in months)

\begin{tabular}{|c|c|c|c|}
\hline State & Baseline & $2+$ Births & Lifetime \\
\hline Alabama & 3 & & \\
\hline Alaska & 12 & 0 & \\
\hline Arizona & 0 & & \\
\hline Arkansas & 3 & & \\
\hline California & 12 & 0 & \\
\hline Colorado & 12 & & \\
\hline Connecticut & 12 & & \\
\hline Delaware & 3 & & \\
\hline District of Columbia & 12 & & \\
\hline Florida & 3 & & \\
\hline Georgia & 12 & 0 & \\
\hline Hawaii & 6 & & \\
\hline Idaho & 0 & & \\
\hline Illinois & 12 & & \\
\hline Indiana & 3 & & \\
\hline Iowa & 2.77 & & \\
\hline Kansas & 12 & & \\
\hline Kentucky & 12 & 0 & \\
\hline Louisiana & 12 & 0 & \\
\hline Maine & 12 & 0 & \\
\hline Maryland & 12 & 0 & \\
\hline Massachusetts & 24 & & \\
\hline Michigan & 3 & & \\
\hline Minnesota & 12 & & \\
\hline Mississippi & 12 & 0 & \\
\hline Missouri & 12 & & \\
\hline Montana & 0 & & \\
\hline Nebraska & 3 & & \\
\hline Nevada & 12 & 0 & \\
\hline New Hampshire & 24 & & \\
\hline New Jersey & 3 & & \\
\hline New Mexico & 12 & 0 & \\
\hline New York & 3 & & \\
\hline North Carolina & 12 & 0 & \\
\hline North Dakota & 4 & & \\
\hline Ohio & 12 & & \\
\hline Oklahoma & 3 & & 12 \\
\hline Oregon & 3 & & \\
\hline Pennsylvania & 12 & 0 & \\
\hline Rhode Island & 12 & & \\
\hline South Carolina & 12 & & \\
\hline South Dakota & 3 & & \\
\hline Tennessee & 4 & & \\
\hline Texas & 24 & & \\
\hline Utah & 0 & & \\
\hline Vermont & 18 & & \\
\hline Virginia & 18 & & \\
\hline Washington & 4 & & 12 \\
\hline West Virginia & 12 & 6 & \\
\hline Wisconsin & 3 & & \\
\hline Wyoming & 3 & & 12 \\
\hline
\end{tabular}


Table 2: Summary Statistics for the Welfare-Eligible Subsample

\begin{tabular}{|c|c|c|c|}
\hline Variable & $\begin{array}{c}\text { Full } \\
\text { Sample }\end{array}$ & $\begin{array}{c}\text { Any Maternal } \\
\text { Work }\end{array}$ & $\begin{array}{l}\text { No Maternal } \\
\text { Work }\end{array}$ \\
\hline Outcome & & & \\
\hline Bailey Short Form mental test score (BSF-R) & $\begin{array}{c}74.73 \\
(10.28)\end{array}$ & $\begin{array}{c}75.38 \\
(10.11)\end{array}$ & $\begin{array}{c}73.84^{*} \\
(10.45)\end{array}$ \\
\hline Family Characteristics & & & \\
\hline Mother's age at childbirth (years) & $\begin{array}{l}26.54 \\
(6.03)\end{array}$ & $\begin{array}{l}26.43 \\
(5.98)\end{array}$ & $\begin{array}{l}26.68 \\
(6.09)\end{array}$ \\
\hline $\begin{array}{l}\text { Mother is high school drop-out at childbirth } \\
(\%)\end{array}$ & $\begin{array}{c}0.254 \\
(0.435)\end{array}$ & $\begin{array}{l}0.197 \\
(0.398)\end{array}$ & $\begin{array}{r}0.331^{*} \\
(0.471)\end{array}$ \\
\hline Mother is married at childbirth (\%) & $\begin{array}{c}0.573 \\
(0.495)\end{array}$ & $\begin{array}{l}0.536 \\
(0.499)\end{array}$ & $\begin{array}{c}0.623^{*} \\
(0.485)\end{array}$ \\
\hline Previous live births (no.) & $\begin{array}{l}1.205 \\
(1.260)\end{array}$ & $\begin{array}{l}1.114 \\
(1.192)\end{array}$ & $\begin{array}{l}1.330^{*} \\
(1.338)\end{array}$ \\
\hline Mother used tobacco during pregnancy (\%) & $\begin{array}{c}0.177 \\
(0.382)\end{array}$ & $\begin{array}{c}(1.172) \\
0.178 \\
(0.382)\end{array}$ & $\begin{array}{c}0.177 \\
(0.381)\end{array}$ \\
\hline WIC participation (\%) & $\begin{array}{c}0.666 \\
(0.472)\end{array}$ & $\begin{array}{l}0.648 \\
(0.478)\end{array}$ & $\begin{array}{r}0.689^{*} \\
(0.463)\end{array}$ \\
\hline English is only language spoken at home (\%) & $\begin{array}{c}0.687 \\
(0.464)\end{array}$ & $\begin{array}{l}0.736 \\
(0.441)\end{array}$ & $\begin{aligned} 0.619^{*} \\
(0.486)\end{aligned}$ \\
\hline Household members ages $18+$ (no.) & $\begin{array}{l}2.226 \\
(0.912)\end{array}$ & $\begin{array}{l}2.212 \\
(0.922)\end{array}$ & $\begin{array}{c}2.244 \\
(0.897)\end{array}$ \\
\hline Urban residence (\%) & $\begin{array}{c}0.824 \\
(0.381)\end{array}$ & $\begin{array}{l}0.816 \\
(0.387)\end{array}$ & $\begin{array}{r}0.834^{*} \\
(0.372)\end{array}$ \\
\hline Reside in a different state (\%) & $\begin{array}{c}0.034 \\
(0.180)\end{array}$ & $\begin{array}{l}0.030 \\
(0.170)\end{array}$ & $\begin{aligned} 0.039^{*} \\
(0.193)\end{aligned}$ \\
\hline $\begin{array}{l}\text { Child Characteristics } \\
\text { Male }(\%)\end{array}$ & $\begin{array}{c}0.517 \\
(0.500)\end{array}$ & $\begin{array}{l}0.516 \\
(0.500)\end{array}$ & $\begin{array}{c}0.518 \\
(0.500)\end{array}$ \\
\hline Age at assessment (months) & $\begin{array}{l}10.56 \\
(1.93)\end{array}$ & $\begin{array}{l}10.61 \\
(1.95)\end{array}$ & $\begin{array}{l}10.49^{*} \\
(1.90)\end{array}$ \\
\hline Black (\%) & $\begin{array}{c}0.184 \\
(0.388)\end{array}$ & $\begin{array}{l}0.211 \\
(0.408)\end{array}$ & $\begin{array}{r}0.147^{*} \\
(0.354)\end{array}$ \\
\hline Low birth weight (\%) & $\begin{array}{c}0.273 \\
(0.446)\end{array}$ & $\begin{array}{l}0.257 \\
(0.437)\end{array}$ & $\begin{array}{l}0.296^{*} \\
(0.457)\end{array}$ \\
\hline Premature (\%) & $\begin{array}{c}0.120 \\
(0.325)\end{array}$ & $\begin{array}{l}0.106 \\
(0.308)\end{array}$ & $\begin{array}{l}0.139^{*} \\
(0.346)\end{array}$ \\
\hline Born in first quarter of $2001(\%)$ & $\begin{array}{l}0.302 \\
(0.459)\end{array}$ & $\begin{array}{l}0.310 \\
(0.462)\end{array}$ & $\begin{array}{c}0.292 \\
(0.455)\end{array}$ \\
\hline
\end{tabular}

Source: Author's analysis of the 9-month wave of the ECLS-B.

Notes: Standard deviations are displayed in parentheses. All summary statistics are reported for the subsample of welfare-eligible children, that is, children whose mothers are either unmarried or have less than a BA degree at childbirth. The column Any Maternal Work refers to any employment by mothers since the birth of the focal child. Mother's age and educational attainment (i.e., high school drop-out) are measured at childbirth, as recorded on the focal child's birth certificate. An asterisk $(*)$ indicates that the null hypothesis of equal means across workers and non-workers is rejected at the 0.10 level or better. 
Table 3: Estimates from the First-Stage Equation

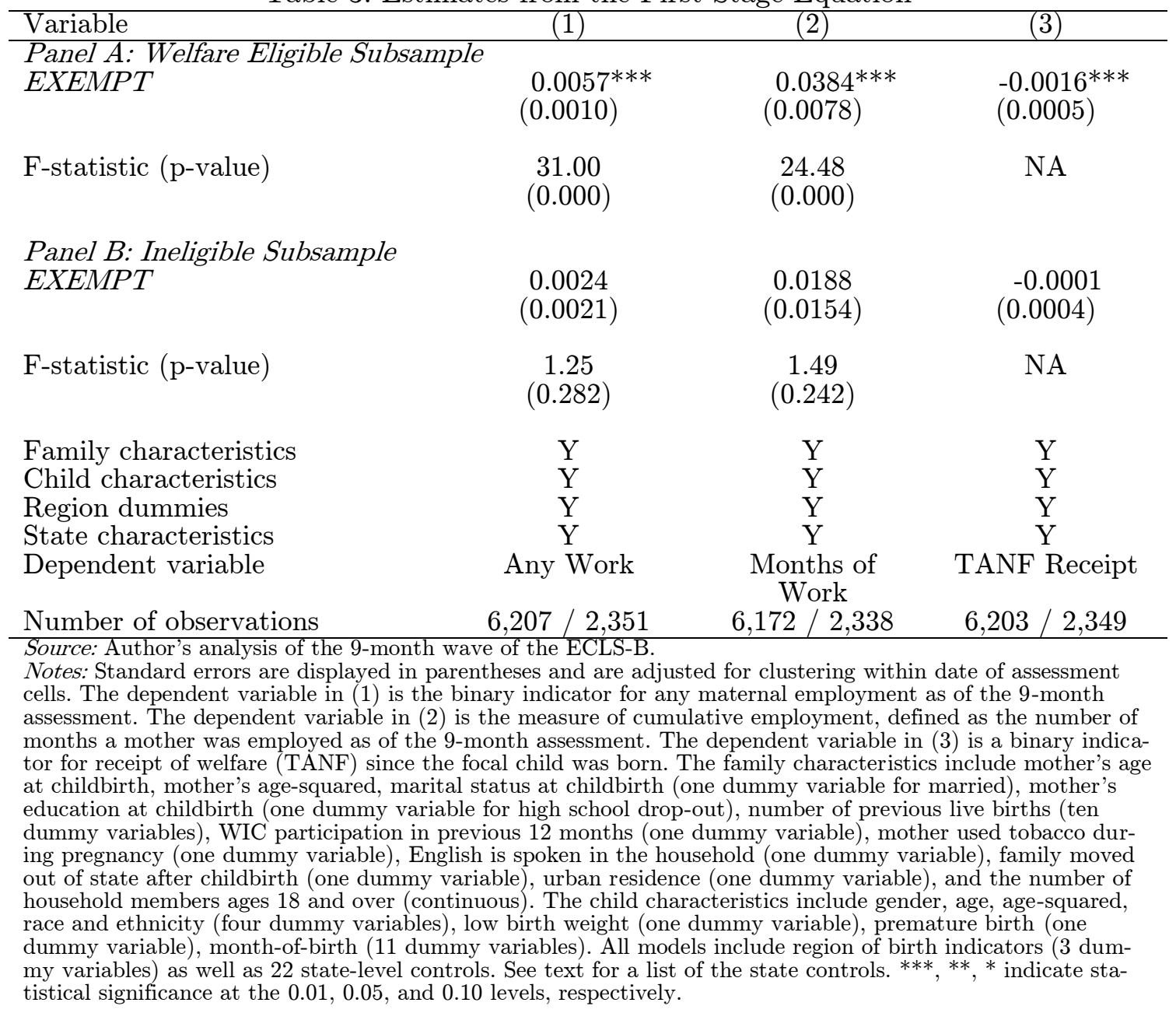


Table 4: Exogeneity Tests on the Instrumental Variable

\begin{tabular}{lc}
\hline Dependent Variable & Coefficient (Std. Error) \\
Mother worked in year prior to childbirth & 0.0016 \\
& $(0.0011)$ \\
Mother attended 16+ prenatal doctor's visits & -0.0015 \\
Mother lived with own biological mother until 16 & $(0.0009)$ \\
& -0.0012 \\
Mother lived with own biological father until 16 & $(0.0014)$ \\
Child's grandmother was a high school drop-out & 0.0013 \\
Child's grandfather was a high school drop-out & $(0.0015)$ \\
Family received WIC in previous 12 months & 0.0010 \\
Child was born in Q1 of 2001 & $(0.0014)$ \\
Child is low birth weight & 0.0013 \\
Child was born prematurely & $(0.0010)$ \\
Child is male & -0.0012 \\
& $(0.0012)$ \\
& -0.0007 \\
& $(0.0016)$ \\
& -0.0002 \\
& $(0.0008)$ \\
& 0.0002 \\
& $(0.0010)$ \\
& -0.0006 \\
& $(0.0015)$ \\
& -0.0002 \\
& $(0.0013)$ \\
& 0.0003 \\
& $(0.0008)$ \\
\hline
\end{tabular}

Source: Author's analysis of the 9-month wave of the ECLS-B.

Notes: Each cell displays the coefficient and standard errors (in parentheses) from a regression of each variable (listed in the first column) on EXEMPT and the full set of controls. Standard errors are adjusted for clustering within date of assessment cells. See the notes in Table 3 for a list of the controls included in the regressions. The regressions are estimated on the subsample of welfare-eligible families. $* * *, * *, *$ indicate statistical significance at the $0.01,0.05$, and 0.10 levels, respectively. 
Table 5: OLS and IV Estimates of the Impact of Early Maternal Work on Children's Cognitive Ability

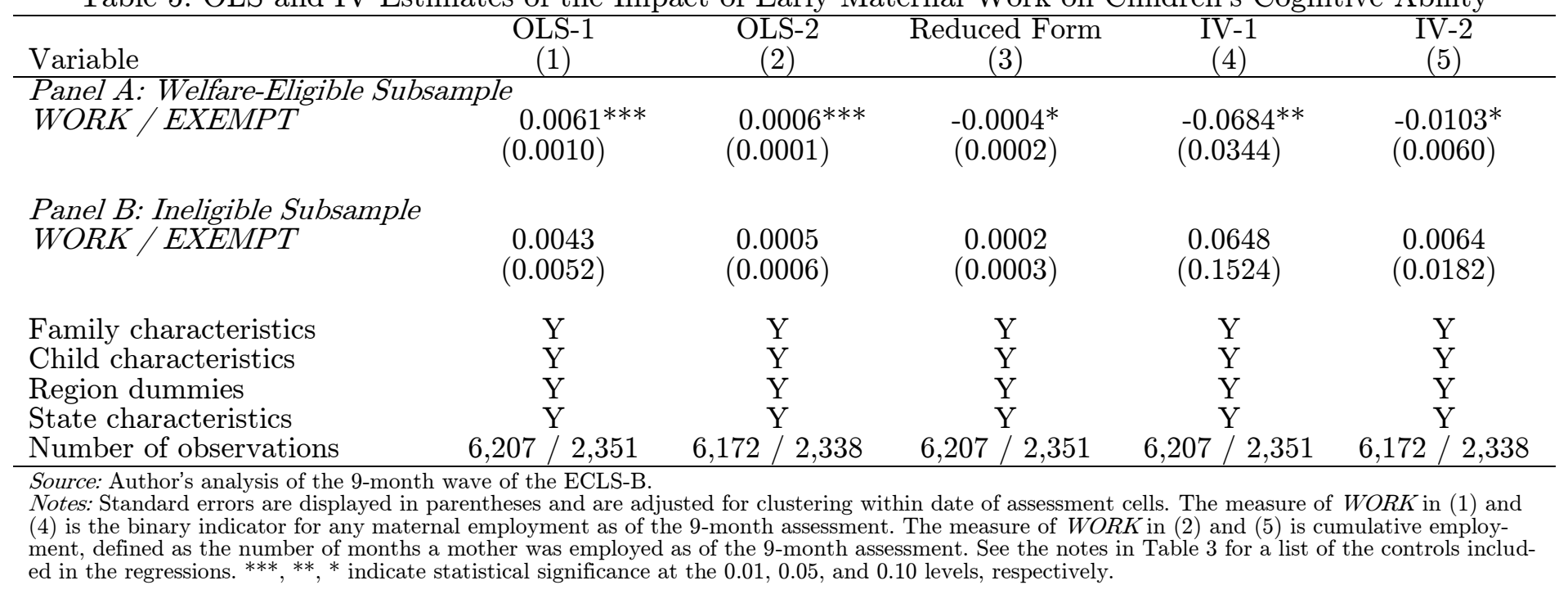


Table 6: Additional Robustness Checks

\begin{tabular}{lcc}
\hline Specification & Any & Cumulative \\
Work \\
\hline (1) Omit the maternal/family controls & $-0.0648^{* *}$ & $-0.0099^{*}$ \\
& $(0.0328)$ & $(0.0058)$ \\
(2) Omit the child controls & $-0.0710^{*}$ & -0.0109 \\
& $(0.0410)$ & $(0.0069)$ \\
(3) Omit both sets of controls & $-0.0732^{*}$ & $-0.0107^{*}$ \\
& $(0.0378)$ & $(0.0061)$ \\
(4) Control for maternity leave status & $-0.0985^{* *}$ & $-0.0177^{*}$ \\
& $(0.0479)$ & $(0.0105)$ \\
(5) Control for pre-birth employment status & $-0.0789^{* *}$ & $-0.0131^{*}$ \\
& $(0.0398)$ & $(0.0078)$ \\
(6) Control for mother's background & $-0.0670^{*}$ & $-0.0101^{*}$ \\
& $(0.0346)$ & $(0.0059)$ \\
(7) Control for number of months of TANF receipt & $-0.0744^{* *}$ & $-0.0116^{*}$ \\
& $(0.0362)$ & $(0.0066)$ \\
(8) Control for other work requirement exemptions & $-0.1047^{* *}$ & $-0.0150^{*}$ \\
& $(0.0476)$ & $(0.0078)$ \\
(9) Remove the marital status sample criterion & $-0.0718^{*}$ & $-0.0108^{*}$ \\
(10) Use more narrow sample criteria & $(0.0376)$ & $(0.0062)$ \\
& -0.0728 & -0.0070 \\
(11) Use alternative instrumental variable & $(0.0696)$ & $(0.0086)$ \\
& $-0.0629^{*}$ & -0.0095 \\
& $(0.0367)$ & $(0.0063)$ \\
\hline
\end{tabular}

Source: Author's analysis of the 9-month wave of the ECLS-B.

Notes: Standard errors are displayed in parentheses and are adjusted for clustering within date of assessment cells. The measure of WORK in column (1) is the binary indicator for any maternal employment as of the 9month assessment. The measure of WORK in column (2) is cumulative employment, defined as the number of months a mother was employed as of the 9-month assessment. The sample criteria used to produce the estimates in row (8) are children born to mothers who are unmarried and who have no more than a high school degree. See the notes in Table 3 for a list of the controls included in the regressions. $* * *, * *, *$ indicate statistical significance at the $0.01,0.05$, and 0.10 levels, respectively. 
Table 7: Mechanisms

\begin{tabular}{|c|c|c|c|c|}
\hline $\begin{array}{l}\text { Outcome Variable } \\
\text { (1) Household income below FPL }\end{array}$ & $\begin{array}{c}\begin{array}{c}\text { Mean } \\
(1)\end{array} \\
0.326 \\
(0.469)\end{array}$ & $\begin{array}{c}\text { Reduced Form } \\
(2) \\
-0.0019^{* *} \\
(0.0008)\end{array}$ & \begin{tabular}{l}
\multicolumn{1}{c}{ IV-1 } \\
\multicolumn{1}{c}{$(3)$} \\
$-0.3214^{* * *}$ \\
$(0.1251)$
\end{tabular} & \begin{tabular}{l}
\multicolumn{1}{c}{$\begin{array}{c}\text { IV-2 } \\
(4)\end{array}$} \\
$-0.0492^{* *}$ \\
$(0.0196)$
\end{tabular} \\
\hline $\begin{array}{l}\text { (2) Maternal health "excellent" or } \\
\text { "very good" }\end{array}$ & $\begin{array}{c}0.609 \\
(0.488)\end{array}$ & $\begin{array}{c}0.0001 \\
(0.0013)\end{array}$ & $\begin{array}{c}0.0086 \\
(0.2155)\end{array}$ & $\begin{array}{c}0.0069 \\
(0.0342)\end{array}$ \\
\hline $\begin{array}{l}\text { (3) Center for Epidemiologic Studies } \\
\text { Depression Scale (CES-D) }\end{array}$ & $\begin{array}{l}5.629 \\
(5.742)\end{array}$ & $\begin{array}{c}0.0119 \\
(0.0127)\end{array}$ & $\begin{array}{l}1.980 \\
(1.798)\end{array}$ & $\begin{array}{c}0.2670 \\
(0.2866)\end{array}$ \\
\hline $\begin{array}{l}\text { (4) Mother felt depressed at least } \\
\text { one day last week }\end{array}$ & $\begin{array}{l}0.337 \\
(0.473)\end{array}$ & $\begin{array}{r}0.0023^{*} \\
(0.0012)\end{array}$ & $\begin{array}{l}0.3666^{* *} \\
(0.1791)\end{array}$ & $\begin{array}{r}0.0530^{*} \\
(0.0321)\end{array}$ \\
\hline (5) Child was breast fed & $\begin{array}{c}0.616 \\
(0.486)\end{array}$ & $\begin{array}{l}-0.0023^{*} \\
(0.0013)\end{array}$ & $\begin{array}{r}-0.4014^{*} \\
(0.2179)\end{array}$ & $\begin{array}{c}-0.0634^{*} \\
(0.0340)\end{array}$ \\
\hline $\begin{array}{l}\text { (6) Nursing Child Assessment } \\
\text { Teaching Scale (NCATS) }\end{array}$ & $\begin{array}{l}33.84 \\
(4.51)\end{array}$ & $\begin{array}{c}0.0133 \\
(0.0133)\end{array}$ & $\begin{array}{c}2.2252 \\
(2.2200)\end{array}$ & $\begin{array}{c}0.3491 \\
(0.3220)\end{array}$ \\
\hline $\begin{array}{l}\text { (7) Child demands constant atten- } \\
\text { tion/needs much help sleeping }\end{array}$ & $\begin{array}{c}0.293 \\
(0.455)\end{array}$ & $\begin{array}{r}0.0025^{*} \\
(0.0012)\end{array}$ & $\begin{array}{r}0.4326^{*} \\
(0.2280)\end{array}$ & $\begin{array}{r}0.0621^{*} \\
(0.0333)\end{array}$ \\
\hline $\begin{array}{l}\text { (8) Family member reads to child at } \\
\text { least once per week }\end{array}$ & $\begin{array}{l}0.846 \\
(0.361)\end{array}$ & $\begin{array}{r}-0.0019^{*} \\
(0.0010)\end{array}$ & $\begin{array}{l}-0.3280^{* *} \\
(0.1676)\end{array}$ & $\begin{array}{r}-0.0553^{*} \\
(0.0315)\end{array}$ \\
\hline $\begin{array}{l}\text { (9) Cumulative number of months } \\
\text { in non-parental child care }\end{array}$ & $\begin{array}{l}3.336 \\
(3.915)\end{array}$ & $\begin{array}{r}0.0189^{*} \\
(0.0107)\end{array}$ & $\begin{array}{l}3.2796^{* *} \\
(1.4122)\end{array}$ & $\begin{array}{r}0.4519^{*} \\
(0.2374)\end{array}$ \\
\hline $\begin{array}{l}\text { (10) Weekly hours spent in all non- } \\
\text { parental child care arrangements }\end{array}$ & $\begin{array}{l}14.68 \\
(20.21)\end{array}$ & $\begin{array}{l}0.0858^{*} \\
(0.0447)\end{array}$ & $\begin{array}{l}14.669^{* * *} \\
(5.557)\end{array}$ & $\begin{array}{l}2.181^{* *} \\
(0.889)\end{array}$ \\
\hline $\begin{array}{l}\text { (11) Child using non-parental child } \\
\text { care in first } 3 \text { months after birth }\end{array}$ & $\begin{array}{l}0.301 \\
(0.459)\end{array}$ & $\begin{array}{l}0.0033^{* * *} \\
(0.0011)\end{array}$ & $\begin{array}{l}0.5691^{* * *} \\
(0.1761)\end{array}$ & $\begin{array}{l}0.0781^{* * *} \\
(0.0224)\end{array}$ \\
\hline
\end{tabular}

Notes: In column (1), standard deviations are displayed in parentheses. In columns (2) through (4), standard errors are displayed in parentheses and are adjusted for clustering within date of assessment cells. The measure of WORK in column (3) is the binary indicator for any maternal employment as of the 9-month assessment. The measure of WORK in column (4) is cumulative employment, defined as the number of months a mother was employed as of the 9-month assessment. Variable definitions, by row number, are as follows: (1) is a binary indicator denoting families below the Federal Poverty Line (FPL); (2) is a binary indicator denoting mothers in excellent or very good overall health; (3) is the mother's score on the 12-item CES-D depression scale; (4) is a binary indicator denoting mothers who "felt depressed" at least one day during the past week (i.e., one of the items on the CES-D); (5) is a binary indicating denoting children who were breast fed (at all) since child birth; (6) is the mother's score on the 50-item NCATS scale of parent-child interactions; (7) is a binary indicator denoting children who, according to parental reports, "sometimes" or "most times" "demands attention and company constantly" and "needs a lot of help to fall asleep;" (8) is a binary indicator denoting that the child is read to by a family member at least one time per week; $(9)$ is the cumulative number of months the child spent in non-parental child care arrangements as of the 9-month assessment; (10) is the total number of hours per week the child spends in all non-parental child care arrangements; and (11) is a binary indicator denoting children who began their first non-parental child care arrangement at some point in the first three years of life. See the notes in Table 3 for a list of the controls included in the regressions. ${ }^{* * *},{ }^{* *},{ }^{*}$ indicate statistical significance at the $0.01,0.05$, and 0.10 levels, respectively. 